\title{
Overview of the Synthesis of MXenes and Other Ultrathin 2D Transition Metal Carbides and Nitrides
}

\author{
Louisiane Verger ${ }^{\mathrm{a} *}$, Chuan $\mathrm{Xu}^{\mathrm{b} *}$, Varun Natu ${ }^{\mathrm{a}}$, Hui-Ming Cheng ${ }^{\mathrm{b}, \mathrm{c}}$, Wencai Ren ${ }^{\mathrm{b}, \mathrm{c}}$, Michel W. \\ Barsoum $^{\mathrm{a}}$
}

*first co-authors

${ }^{a}$ Department of Materials Science and Engineering, Drexel University, Philadelphia, Pennsylvania 19104, United States

${ }^{b}$ Shenyang National Laboratory for Materials Science, Institute of Metal Research, Chinese Academy of Sciences, Shenyang 110016, P. R. China

${ }^{c}$ School of Materials Science and Engineering, University of Science and Technology of China, 72 Wenhua Road, Shenyang 110016, P. R. China

Corresponding authors: Michel W. Barsoum (barsoumw@drexel.edu) College of Engineering, Drexel University, LeBow 444, 3141 Chestnut Street, Philadelphia, PA 19104

and Wencai Ren (wcren@imr.ac.cn) Shenyang National Laboratory for Materials Science, Institute of Metal Research, Chinese Academy of Sciences, Shenyang 110016, P. R. China

Keywords: MXenes; 2D materials; top-down synthesis; bottom-up synthesis;

\begin{abstract}
:
In 2011, a new family of two dimensional (2D) carbides, carbonitrides and nitrides - labeled MXenes - was discovered. Since then the number of papers on these materials has increased exponentially for several reasons amongst them: their hydrophilic nature, excellent electronic conductivities and ease of synthesizing large quantity in water. This unique combination of properties and ease of processing has positioned them as enabling materials for a large and quite
\end{abstract}


varied host of applications from energy storage to electromagnetic shielding to transparent conductive electrodes, electrocatalysis, to name a few. Since the initial synthesis of $\mathrm{Ti}_{3} \mathrm{C}_{2}$ in hydrofluoric acid, many more compositions were discovered, and different synthesis pathways were explored. Most of the work done so far has been conducted on top-down synthesis where a layered parent compound is etched and then exfoliated. Three bottom-up synthesis methods, chemical vapor deposition, a template method and plasma enhanced pulsed laser deposition have been reported. The latter methods enable the synthesis of not only high-quality thin $2 \mathrm{D}$ transition metal carbide and nitride films, but also those that could not be synthesized by selective etching. This article reviews and summarizes the most important breakthroughs in the synthesis of MXenes and high-quality thin 2D transition metal carbide and nitride films.

\section{Highlights:}

- Currently MXenes constitute a family of 2D materials of about 30 different compositions obtained by top-down synthetic methods. The vast majority of these compositions involve the etching of a MAX phase using a F-ion containing solution such as $\mathrm{HF}$ or $\mathrm{LiF}$ and $\mathrm{HCl}$.

- Bottom-up synthesis enables the production of not only high-quality thin $2 \mathrm{D}$ transition metal carbide and nitride films but also those that could not be synthesized by selective etching.

- Different synthesis pathways have been reported that avoid the use of hazardous HF, mainly for the most studied compound $\mathrm{Ti}_{3} \mathrm{C}_{2}$.

- The possibility of solid solutions of the M and X sites, and chemical order in and out of plane in the MAX phases has greatly expanded the chemistry of MXenes.

\section{Introduction}

Over the last decade, two dimensional (2D) materials has garnered their fair share of research interest due to their exciting physical and chemical properties and extensive application potential ${ }^{1}$. Since the first synthesis of graphene ${ }^{2}$, the field has broadened to many other 2D materials, such as boron nitride ${ }^{3}$, metal dichalcogenides ${ }^{4}$, halides ${ }^{5}$ and oxides ${ }^{6}$ among others. 
One of the most recent addition to the 2D family of materials are transition metal carbides, carbonitrides and nitrides (MXenes) ${ }^{7}$. Their formula can be $\mathrm{M}_{1.33} \mathrm{XT}_{\mathrm{z}}$ or $\mathrm{M}_{\mathrm{n}+1} \mathrm{X}_{\mathrm{n}} \mathrm{T}_{\mathrm{z}}(\mathrm{n}=$ 1, 2 or 3), where $\mathrm{M}$ is an early transition metal, $\mathrm{X}$ is $\mathrm{C}$ and/or $\mathrm{N}$ and $\mathrm{T}_{\mathrm{z}}$ represents various possible terminations (mainly hydroxyl, -OH, oxygen, -O and/or fluorine, -F). They were dubbed MXenes because the vast majority of them are obtained by etching the Al layers from the MAX phases and their $2 \mathrm{D}$ nature ${ }^{8}$. The MAX phases in turn are layered hexagonal transition metal carbide and nitrides ${ }^{9}$. As noted above, the first MXene, $\mathrm{Ti}_{3} \mathrm{C}_{2} \mathrm{~T}_{\mathrm{z}}$ was produced in 2011 by placing $\mathrm{Ti}_{3} \mathrm{AlC}_{2}$ powders in concentrated $\mathrm{HF}$ for a few hours at room temperature ${ }^{8}$. A year later, the universality of etching Al from many other MAX phases gave birth to MXenes ${ }^{7}$. Soon thereafter, MXenes showed great promise in a host of applications such as electrochemical energy storage ${ }^{10}$, with notably high capacitances ${ }^{11}$, structural composites ${ }^{12}$, electromagnetic interference shielding ${ }^{13,14}$, water purification ${ }^{15}$, biosensors ${ }^{16}$, transparent conductive electrodes, among many more ${ }^{17}$.

In general, there are two methods to synthesize 2D materials. The first is a bottom-up approach, such as chemical vapor deposition (CVD) that can produce high-quality films on various substrates. This approach is not generally used to make MXenes, because the films obtained are not single layer, but rather very thin films. For example, Xu et al. ${ }^{18}$ used chemical vapor deposition (CVD) to produce thin $\mathrm{Mo}_{2} \mathrm{C}, \mathrm{WC}$ and $\mathrm{TaC}$ films. However, even the thinnest $\mathrm{Mo}_{2} \mathrm{C}$ films were comprised of at least six $\mathrm{Mo}_{2} \mathrm{C}$ layers and not single MXenes sheets. This comment notwithstanding, it is one that should be pursued since in other systems it has been shown to yield high quality films ${ }^{19,20}$. This approach is discussed in some detail in part 2.

The second approach, is a top-down approach, involving the exfoliation of layered solids. This approach can be further divided into mechanical and chemical exfoliation. An example of the former is the use of adhesive tape to separate the graphene layers ${ }^{2}$. This approach is unsuitable for the MAX phases for the simple reason that - in contrast to most other 3D solids used as precursors to their 2D counterparts - the bonds between the $\mathrm{M}$ elements and $\mathrm{Al}$ are for, the most part, strong covalent/metallic. Many Al-based MAX phases are synthesized at temperatures higher than $1300{ }^{\circ} \mathrm{C} 9$. Since this approach is inapplicable here it will not be discussed further. It is worth noting that prior to the MXene discovery, conventional wisdom had it that only weakly bonded 3D solids can be exfoliated. In that sense, the MXene discovery was paradigm shifting. 
The key to converting weakly bonded 3D solids to their 2D counterparts using the topdown approach is to weaken the interlayer bonds. One approach is to intercalate the layers to the point that they can be readily dispersed in a solvent. The main challenge thus lies in finding the right combination of intercalant and solvent ${ }^{1}$. This approach - most usually carried out in liquids - is by far the preferred one when large quantities of material are needed. Four main types of liquid exfoliation methods are usually described in the literature. The first consists in treating the 3D layered solid with an oxidizer and the resulting material is then dispersed in the appropriate solvent. Graphene oxide (GO) is synthesized by this method, using sulfuric acid and permanganate potassium as the oxidizers and water as the solvent ${ }^{21}$. A second method relies on the fact that the 3D layered solid can host various ionic species and/or guest molecules between the layers. Once that is accomplished the concomitant swelling can sufficiently weaken the interlayer attraction and lead to a 2D dispersion. Additional energetic treatment (shear, agitation, sonication) is sometimes needed to separate the 2D layers. For example, $\mathrm{MoS}_{2}$ can be dispersed by this method ${ }^{22}$. Some layered materials already contain cationic counter ions that compensate their surface layer charges. For these solids, a third method entailing exchanging the intrinsic cations with, typically, larger ions, can result in the separation of the nanosheet under vigorous stirring. Vermiculite ${ }^{23}$ or birnessite-type layered manganese oxides ${ }^{24}$ can be exfoliated using this method. The last, and most recent method, consists in directly exposing the 3D layered material to ultrasonic waves in a solvent that prevents their re-aggregation. This method was used on graphite using N-methylpyrrolidone (NMP) as a solvent for instance ${ }^{25}$. Since as noted above, MXenes are mostly derived from the MAX phases, in which the M-A layers are quite strongly bound to each other by a combination of covalent and metallic bonds ${ }^{9}$ neither mechanical nor classical chemical exfoliation is possible. What is required in this case is to first selectively etch the A layers (Figure 1).

The purpose of this work is to give a brief overview of the different MXenes synthesized so far and some of their characteristics, with a focus on the different synthetic pathways used to obtain them. We will first describe top-down synthesis and some of the characteristics of the MXenes obtained, before focusing on the bottom-up approaches. This article complements existing review on MXenes, focused on energy storage ${ }^{17,26,27}$, thin film production ${ }^{28}$, electrical and optical properties ${ }^{29}$, or composites ${ }^{30}$. 

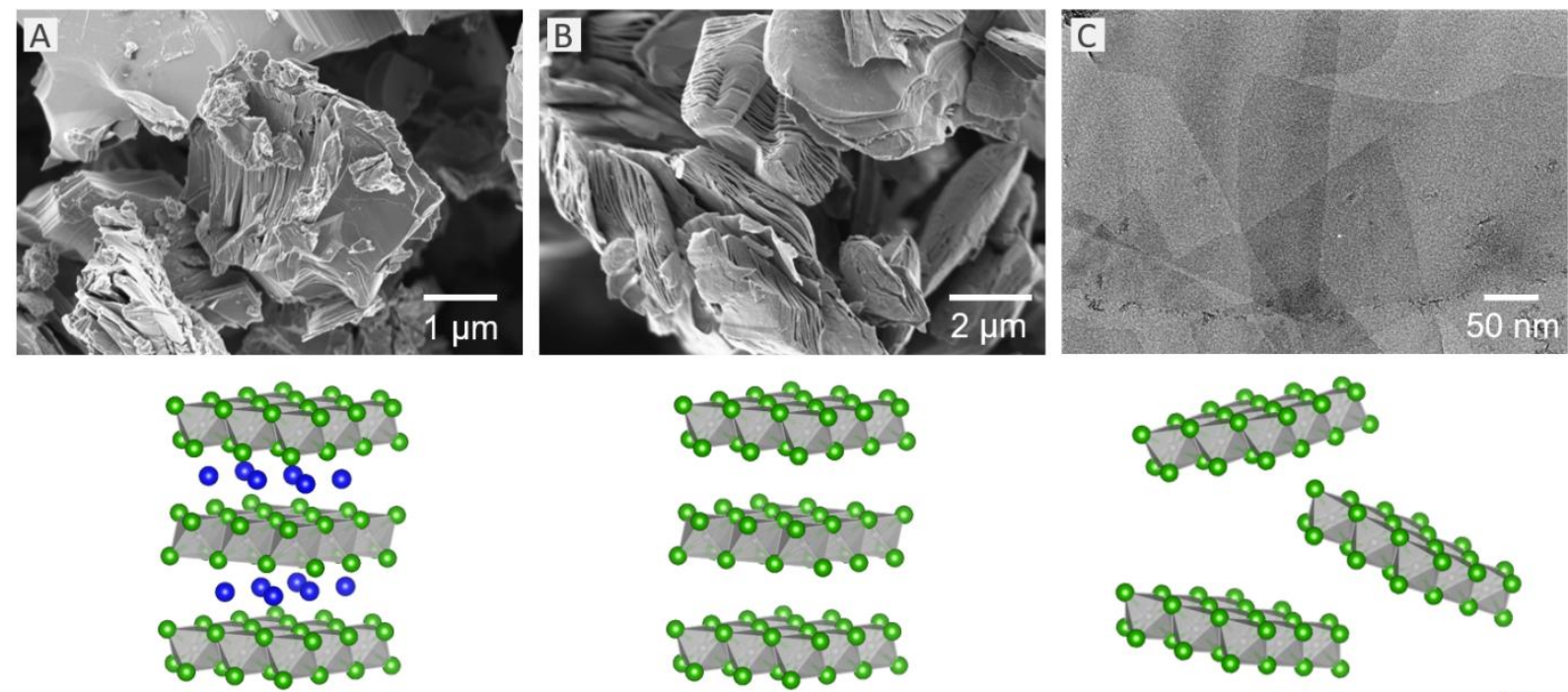

Etching

Figure 1: Pathway to obtain 2D MXene single flakes by top-down synthesis. (A) to (B): First, selective etching of atomic layer $(s)$ from a $3 D$ layered precursor is required $((A)$ is a scanning electron microscope (SEM) micrograph of $\mathrm{Ti}_{3} \mathrm{AlC}_{2}$ particles. (B) SEM picture of $\mathrm{Ti}_{3} \mathrm{C}_{2} \mathrm{~T}_{z}$ multilayer after etching of the $\mathrm{Al}$ layer. (C): Transmission electron microscope (TEM) micrograph of overlapping $\mathrm{Ti}_{3} \mathrm{C}_{2} \mathrm{~T}_{z}$ single layers. Schematics of the MAX to multilayers MXene transformation and their exfoliation are shown in bottom row.

\section{Synthesis of MXenes by top-down approaches}

Since the original discovery in 2011 of the first MXene, $\mathrm{Ti}_{3} \mathrm{C}_{2} \mathrm{~T}_{\mathrm{z}}$, this family of $2 \mathrm{D}$ materials has expanded quite fast and today about 30 different compositions have been synthesized with more being discovered on a routine basis. Figure 2 and Figure 3 summarize the different MXenes obtained to date, their precursors, etching methods and highlights.

\subsection{Precursors}

The MAX phases constitute a large family of currently > 130 different compositions, the vast majority of which crystallize in the $P 6_{3} / \mathrm{mmc}$ space group ${ }^{9}$ or derivatives thereof. The structure is composed of $\mathrm{MX}_{6}$ octahedra, interleaved with pure A layers. The main difference between the three types of MAX phases, viz. $n=1,2$ or 3, is in the number of M layers ( 2 to 4 ) between the A layers. They are typically referred to as 211,312 or 413 , respectively. 
Of the $~ 30$ different MXenes currently known, all but a handful are obtained by etching the Al layers from Al-containing MAX phases. There are a few exceptions. For example, Si etching of $\mathrm{Ti}_{3} \mathrm{SiC}_{2}$ yields $\mathrm{Ti}_{3} \mathrm{C}_{2} \mathrm{~T}_{\mathrm{z}}{ }^{31}$. The starting material to synthesize $\mathrm{Mo}_{2} \mathrm{CT}_{\mathrm{z}}$ is $\mathrm{Mo}_{2} \mathrm{Ga}_{2} \mathrm{C}$ 32,33. And while technically speaking $\mathrm{Mo}_{2} \mathrm{Ga}_{2} \mathrm{C}$ is not a MAX phase, its structure is quite similar to the 211 structure, except that the $\mathrm{MoC}_{6}$ octahedra are interleaved by two Ga layers instead of one. More recently, another class of layered solids was used as precursors, viz. $(\mathrm{MC})_{n} \mathrm{Al}_{3} \mathrm{C}_{2}$ and $(\mathrm{MC})_{\mathrm{n}}(\mathrm{Al}, \mathrm{Si})_{4} \mathrm{C}_{3}$, where $\mathrm{Al}_{3} \mathrm{C}_{3}$ and $(\mathrm{Al}, \mathrm{Si})_{4} \mathrm{C}_{4}$ were etched to yield $\mathrm{Zr}_{3} \mathrm{C}_{2} \mathrm{~T}_{\mathrm{z}}$ and $\mathrm{Hf}_{3} \mathrm{C}_{2} \mathrm{~T}_{\mathrm{z}}$, respectively ${ }^{34,35}$.

The chemical or structural order in MXenes is directly linked to the order in the parent phase. Roughly a third ( 50) of the known MAX phases to date were discovered by Nowotny and coworkers in the sixties ${ }^{36}$. Up to the end of 2014, the only MAX phase solid solutions known on the $\mathrm{M}$ sites were random solid solutions ${ }^{37,38}$, such as the 211 phases $\left(\mathrm{Ti}_{\mathrm{x}} \mathrm{Nb}_{1-\mathrm{x}}\right)_{2} \mathrm{AlC}{ }^{37}$ and $\left(\mathrm{Ti}_{\mathrm{x}} \mathrm{Cr}_{1-\mathrm{x}}\right)_{2} \mathrm{AlC}{ }^{39}$, the 312 phase $\left(\mathrm{Ti}_{1 / 2} \mathrm{~V}_{1 / 2}\right)_{3} \mathrm{AlC}_{2}$, and the 413 phase $\left(\mathrm{Cr}_{5 / 8} \mathrm{Ti}_{3 / 8}\right)_{4} \mathrm{AlC}_{3}{ }^{40}$, etc.

In 2014 and 2017, respectively, two new chemically ordered quaternary MAX phases were discovered: (i) out-of-plane ordered, labeled $o$-MAX, 312 and 413 phases and more recently, (ii) in-plane ordered, labeled $i$-MAX, 211 phases. In the former, a single layer or double layer of one metal element is sandwiched between a layer of another $M$ element (see Figure 3) 40,41. Examples include $\left(\mathrm{Cr}_{2 / 3} \mathrm{Ti}_{1 / 3}\right)_{3} \mathrm{AlC}_{2}, \quad\left(\mathrm{Mo}_{2 / 3} \mathrm{Ti}_{1 / 3}\right)_{3} \mathrm{AlC}_{2}, \quad\left(\mathrm{Mo}_{1 / 2} \mathrm{Ti}_{1 / 2}\right)_{4} \mathrm{AlC}_{3}$ and $\left(\mathrm{Mo}_{2 / 3} \mathrm{Sc}_{1 / 3}\right)_{3} \mathrm{AlC}_{2}$, where the $\mathrm{Ti}$ or Sc layers are located in the inner layers and the Mo on the outside $^{42,43}$. In the $i$-MAX, the two M elements are in plane ordered (Figure 2). The quaternary $\left(\mathrm{Mo}_{2 / 3} \mathrm{Sc}_{1 / 3}\right)_{2} \mathrm{AlC}$ is such a phase ${ }^{44}$. The space group used to describe this structure is $C 2 / c$. The quaternaries, $\left(\mathrm{Mo} / 3 \mathrm{Y}_{1 / 3}\right)_{2} \mathrm{AlC}$ and $\left(\mathrm{V}_{2 / 3} \mathrm{Zr}_{1 / 3}\right)_{3} \mathrm{AlC}_{2}$ were also just discovered ${ }^{45}$, followed by two $\mathrm{W}$-based phases, viz. $\left(\mathrm{W}_{2 / 3} \mathrm{Sc}_{1 / 3}\right)_{2} \mathrm{AlC}$ and $\left(\mathrm{W}_{2 / 3} \mathrm{Y}_{1 / 3}\right)_{2} \mathrm{AlC}{ }^{46}$. Most recently 11 Mo-based rare earth containing $i$-MAX phases were also discovered ${ }^{47}$.

\subsection{Etching}

In the MAX to MXene transformation, the etched layers are always replaced by various termination groups $\mathrm{T}_{\mathrm{z}}$ such as hydroxyl $(-\mathrm{OH})$, oxygen $(-\mathrm{O})$ or fluorine $(-\mathrm{F})$. The material obtained after etching thus consists of $\mathrm{M}_{\mathrm{n}+1} \mathrm{X}_{\mathrm{n}} \mathrm{T}_{\mathrm{z}}$ multilayers (see Figure 1B) held together by 
hydrogen and/or van der Waals bonds. The different etching methods are described in this section.

The ternary, $\mathrm{Ti}_{3} \mathrm{AlC}_{2}$, is not only the first MAX to be etched ${ }^{8}$, but also remains, by far, the most studied, and a variety of etching methods have been developed to convert it to $\mathrm{Ti}_{3} \mathrm{C}_{2} \mathrm{~T}_{\mathrm{Z}}$ (see Figure 3). The first synthesis ${ }^{8}$ consisted of immersing $\mathrm{Ti}_{3} \mathrm{AlC}_{2}$ powders in 50 wt. $\%$ hydrofluoric acid (HF). The M-A bonds and the M-X bonds reacted differently toward HF, resulting in the selective etching of the Al layers. HF etching was then successfully applied to obtain a wide variety of MXenes 7,33,52-54,34,35,42,44,48-51 (see Figure 2 and Figure 3) and remains the most common synthetic pathway. The etching conditions, however, depend on the chemistry and structure of the parent phase. For example, $50 \mathrm{wt} \% \mathrm{HF}$, used on $\mathrm{Ti}_{2} \mathrm{AlC}$, results in its total dissolution. The same is true for $\mathrm{Cr}_{2} \mathrm{AlC}$. However, by decreasing the HF concentration down to 10 wt. $\%, \mathrm{Ti}_{2} \mathrm{CT}_{\mathrm{z}}$ can be obtained ${ }^{7}$, but this remains unsuccessful on $\mathrm{Cr}_{2} \mathrm{AlC}$. Modifying the $\mathrm{HF}$ concentration during etching of the $\left(\mathrm{Mo}_{2 / 3} \mathrm{Y}_{1 / 3}\right)_{2} \mathrm{AlC} i$-MAX phase enables the selective etching of either only the $\mathrm{Al}(10 \mathrm{wt} . \% \mathrm{HF})$ layers or, both the $\mathrm{Al}$ and $\mathrm{Y}(50 \mathrm{wt} . \% \mathrm{HF})$ layers ${ }^{49}$.

$\mathrm{HF}$ is a corrosive chemical, able to penetrate through skin, muscle tissue and bones, making its handling and disposal hazardous ${ }^{55}$. Different synthesis pathways have been explored to avoid or minimize the use of concentrated HF. One of the most widely used is a mixture of hydrochloric acid $(\mathrm{HCl})$ and a fluoride salt, that forms $\mathrm{HF}$ in-situ. Ghidiu et al. first introduced this method using lithium fluoride $(\mathrm{LiF})$ and $\mathrm{HCl}$ on $\mathrm{Ti}_{3} \mathrm{AlC}_{2}{ }^{56}$, and highlighted the analogy of MXenes with clays. Other fluoride salts have also been successfully used $\left(\mathrm{NaF}, \mathrm{KF}\right.$ and $\mathrm{NH}_{4} \mathrm{~F}$ 57,58 ), as well as different $\mathrm{HCl}$ concentrations and $\mathrm{LiF} / \mathrm{HCl}$ molar ratios ${ }^{59}$. Ammonium hydrogen bifluoride $\left(\mathrm{NH}_{4} \mathrm{HF}_{2}\right)$ was also used early on as an alternative to $\mathrm{HF}$ to etch $\mathrm{Al}$ from $\mathrm{Ti}_{3} \mathrm{AlC}_{2}$. It was firstly implemented on thin epitaxial $\mathrm{Ti}_{3} \mathrm{AlC}_{2}$ films ${ }^{60}$, and then used on powders ${ }^{61}$.

Electrochemical etching in dilute $\mathrm{HCl}$ was carried out on $\mathrm{Ti}_{2} \mathrm{AlC}$ to yield $\mathrm{Ti}_{2} \mathrm{CT}_{\mathrm{z}}$ multilayers, but with the presence of carbide-derived carbon ${ }^{62}$. Another F-free etching method based on the anodic corrosion of $\mathrm{Ti}_{3} \mathrm{AlC}_{2}$ in an electrolyte mixture of $\mathrm{NH}_{4} \mathrm{Cl}$ and tetramethylammonium hydroxide $(\mathrm{TMAOH})$ has been reported with a yield of $>40 \%{ }^{63}$. Two new articles have been made available online through archive ${ }^{64,65}$, where the authors describe the synthesis of fully Cl-terminated $\mathrm{Ti}_{3} \mathrm{C}_{2} \mathrm{~T}_{\mathrm{z}}$ and $\mathrm{Ti}_{2} \mathrm{CT}_{\mathrm{z}}$ MXenes from the reaction of $\mathrm{Ti}_{3} \mathrm{AlC}_{2}$ and $\mathrm{Ti}_{2} \mathrm{AlC}$, respectively, in a Lewis acidic melt, such as $\mathrm{ZnCl}_{2}$. 
Until recently, Al was the only element etched from the A layers of the MAX phases. Alhabeb et al. showed for the first time the selective etching of Si from the MAX phase $\mathrm{Ti}_{3} \mathrm{SiC}_{2}$ 31. A mixture of $\mathrm{HF}$ and an oxidant (such as hydrogen peroxide, $\mathrm{H}_{2} \mathrm{O}_{2}$ ) was used. This new approach widens the type of MAX precursors possible, but the method needs to be optimized to increase the yields and quality of the 2D flakes obtained.

The $\mathrm{HF}$ and $\mathrm{HCl} / \mathrm{LiF}$ etching methods are typically performed at temperatures $<60{ }^{\circ} \mathrm{C}$. It is also possible to obtain MXenes at higher temperatures. An alkali-assisted hydrothermal method (using $27.5 \mathrm{M} \mathrm{NaOH}$ at $270{ }^{\circ} \mathrm{C}$ ) was used to produce $\mathrm{Ti}_{3} \mathrm{C}_{2} \mathrm{~T}_{\mathrm{z}}$. The first nitride MXene $\mathrm{Ti}_{4} \mathrm{~N}_{3} \mathrm{~T}_{\mathrm{Z}}$ - was synthesized by heating $\mathrm{Ti}_{4} \mathrm{AlN}_{3}$ powders in a molten salt eutectic mixture of $\mathrm{LiF}$, sodium fluoride $(\mathrm{NaF})$, and potassium fluoride $(\mathrm{KF})$ at $550{ }^{\circ} \mathrm{C}$, under argon (Ar) ${ }^{66}$. More recently, $\mathrm{V}_{2} \mathrm{NT}_{\mathrm{z}}$ and $\mathrm{Mo}_{2} \mathrm{NT}_{\mathrm{z}}$ were obtained by the ammoniation of the carbides $\mathrm{V}_{2} \mathrm{CT}_{\mathrm{z}}$ and $\mathrm{Mo}_{2} \mathrm{CT}_{\mathrm{z}}$ at $600{ }^{\circ} \mathrm{C}^{67}$. 


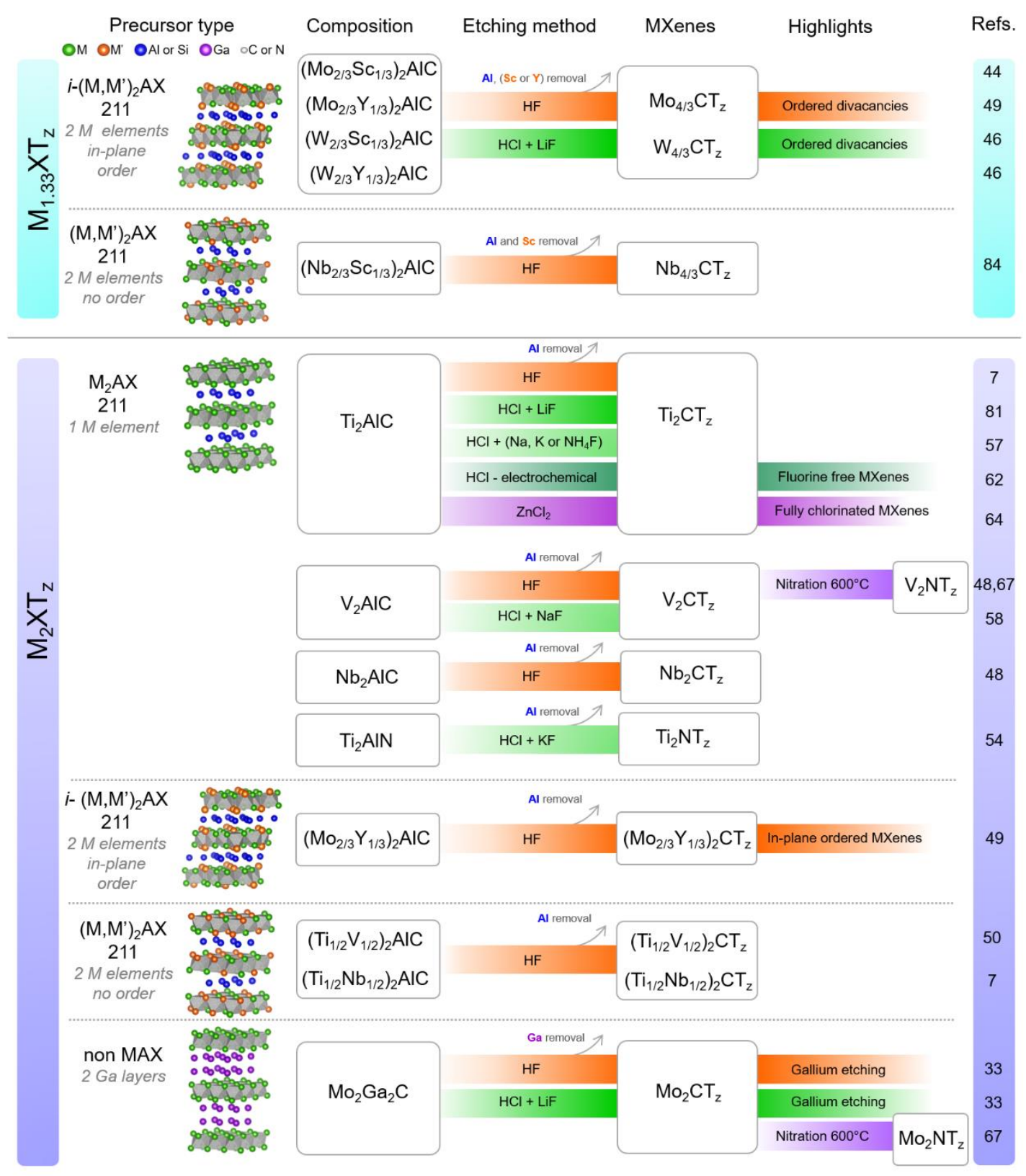

Figure 2: The MXene family - part 1/2. Summary of existing MXenes with $M_{1.33} X T_{z}$ and $M_{2} X T_{z}$ compositions. Precursors, etching method used to obtain them, and highlights are shown. 


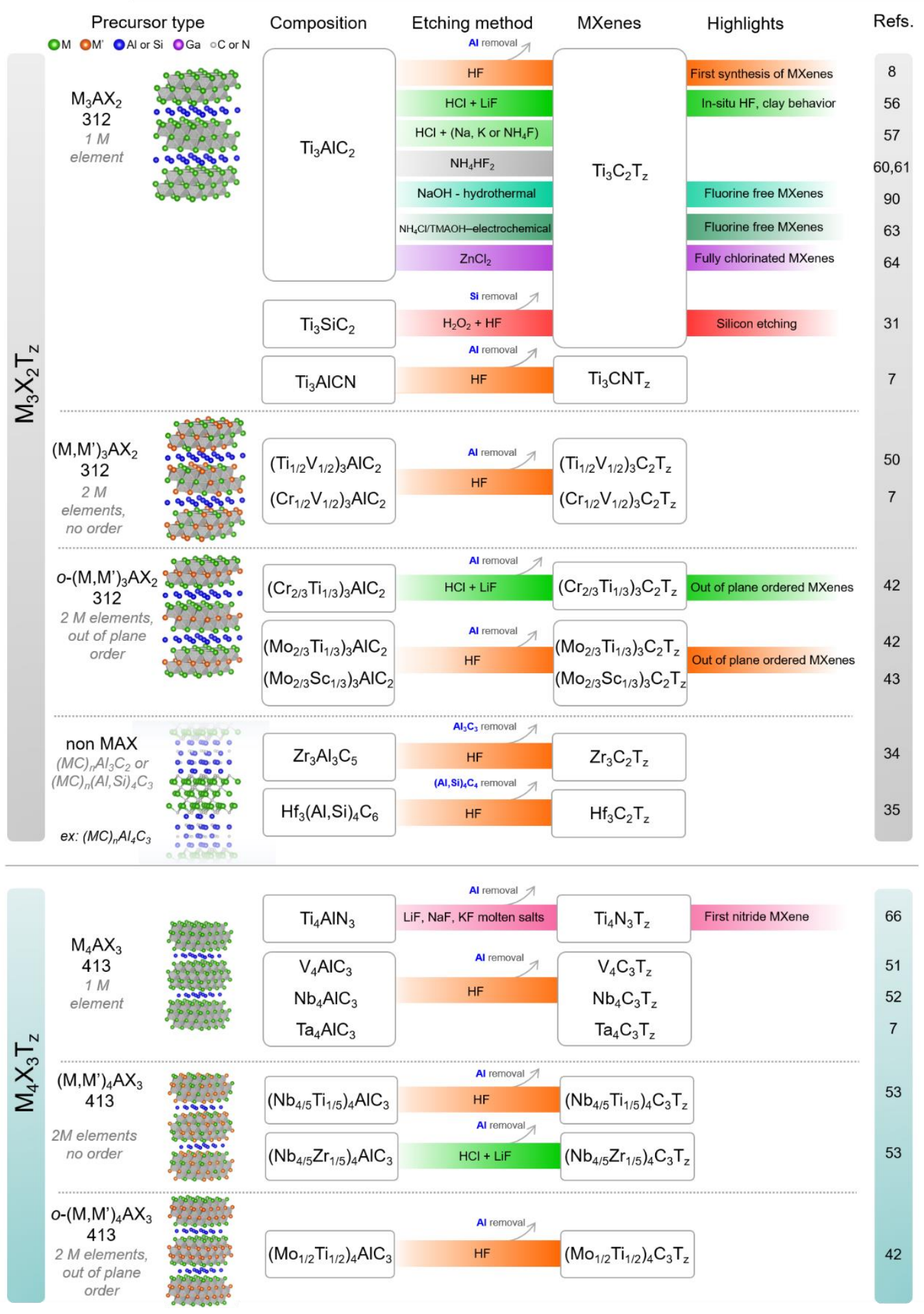

Figure 3: The MXene family - part 2/2. Summary of MXenes with $M_{3} X_{2} T_{z}$ and $M_{4} X_{3} T_{z}$ compositions. Precursors, etching method used to obtain them, and highlights are shown. 


\subsection{Exfoliation}

After etching, the resulting multilayers (Figure $1 \mathrm{~B}$ ) are typically washed several times with water to remove the etching solution containing the byproducts of the synthesis, such as aluminum fluoride $\left(\mathrm{AlF}_{3}\right)^{8}$. An acid-prewash with $\mathrm{HCl}$, or sulfuric acid $\left(\mathrm{H}_{2} \mathrm{SO}_{4}\right)$, can also be used to help dissolve salts such as $\mathrm{AlF}_{3}$ or $\mathrm{LiF}^{66,68}$. It is only then that it is possible to exfoliate the multilayers and obtain colloidal suspensions comprised of single or a few MXene layers (Figure $1 \mathrm{C}$ ). The exfoliation techniques used depend on, (i) etching method and, (ii) MXene composition.

When multilayers are obtained by etchants other than $\mathrm{HCl} / \mathrm{LiF}$, direct sonication can be used to exfoliate them but the yields are quite low ${ }^{8}$. Liquid exfoliation by the intercalation of molecules is then the main method used to obtain colloids with high yield (up to $20 \mathrm{mg}$ of MXenes per $\mathrm{mL}$ of solution). Similar to clays, the multilayers can host various cations and organic molecules ${ }^{68-70}$. The introduction of the proper molecules can induce swelling of the interlayer space and a concomitant weakening of the inter-layer interactions which, as noted above, is key to exfoliating multilayers into single nanosheets on a large scale. Additional energetic treatments, such as sonication or shaking, can also lead to the exfoliation of MXenes and their dispersion in water or other solvents (see Figure 4 A).

The polar organic molecule dimethyl sulfoxide (DMSO) has been used to exfoliate $\mathrm{Ti}_{3} \mathrm{C}_{2} \mathrm{~T}_{\mathrm{z}}{ }^{70}$ and $\left(\mathrm{Mo}_{2 / 3} \mathrm{Ti}_{1 / 3}\right)_{3} \mathrm{C}_{2} \mathrm{~T}_{\mathrm{z}}{ }^{42}$. Expansion of the interlayer space is evidenced by a shift to lower angle $2 \theta$ of the $(00 l)$ peaks in X-ray diffraction (XRD) patterns. Note that the position of the (0002) peaks in the XRD patterns corresponds to half the $c$ lattice parameter and is henceforth referred to simply as the interlayer $d$-spacing. For example, the intercalation of DMSO results in an increase of the $d$-spacing in $\mathrm{Ti}_{3} \mathrm{C}_{2} \mathrm{~T}_{\mathrm{z}}$ from $9.8 \AA$ to $17.6 \AA$ (see Figure $4 \mathrm{~B}$ ) 70. The $d$-spacing can even increase further to $22.4 \AA$ with the co-intercalation of water. For reasons that are not completely clear, apart from these two MXene compositions, DMSO is not effective for other MXenes.

However, $\mathrm{Nb}_{2} \mathrm{CT}_{\mathrm{z}}$ can be exfoliated via the intercalation of isopropylamine ${ }^{71}$. The exfoliation using tetrabutylammonium hydroxide (TBAOH), commonly used for other 2D materials ${ }^{72}$, was first proven on $\mathrm{V}_{2} \mathrm{CT}_{\mathrm{z}}$ and $\mathrm{Ti}_{3} \mathrm{CNT}_{\mathrm{z}}{ }^{73}$. This method relies on the intercalation of $\mathrm{TBA}^{+}$ions in the interlayer space. Other large organic base molecules, such as choline hydroxide 
and $n$-butylamine were also used for $\mathrm{V}_{2} \mathrm{CT}_{\mathrm{z}}{ }^{73}$. TBAOH was then successfully used to exfoliate many more MXene compositions, such as $\left(\mathrm{Mo}_{2 / 3} \mathrm{Ti}_{1 / 3}\right)_{3} \mathrm{C}_{2} \mathrm{~T}_{\mathrm{z}}$ and $\left(\mathrm{Mo}_{1 / 2} \mathrm{Ti}_{1 / 2}\right)_{4} \mathrm{C}_{3} \mathrm{~T}_{\mathrm{z}}{ }^{74}, \mathrm{Ti}_{4} \mathrm{~N}_{3} \mathrm{~T}_{\mathrm{z}}{ }^{66}$, $\mathrm{Mo}_{2} \mathrm{CT}_{\mathrm{z}}{ }^{33}$. Interestingly, TBAOH does not exfoliate $\mathrm{Ti}_{3} \mathrm{C}_{2} \mathrm{~T}_{\mathrm{z}}$ but TMAOH does ${ }^{59}$.

And while these results clearly show that different intercalants are needed to produce MXene colloidal suspensions, there are other more effective and simpler routes. A major attraction of the $\mathrm{HCl} / \mathrm{LiF}$ etching method - in addition to eliminating $\mathrm{HF}$ and its hazards - is that it not only etches the Al layer, but enables the, almost simultaneous, exfoliation of the multilayers by the introduction of $\mathrm{Li}^{+}$and its water of hydration in the interlayer space (see Figure $4 \mathrm{~A}$ ). The $d$-spacing of dry multilayers obtained with the $\mathrm{HCl} / \mathrm{LiF}$ method is close to 13 $\AA$, at least $3 \AA$ larger than multilayers etched with HF alone ${ }^{56}$ (see Figure 4 B). When the multilayers are wet, viz. never dried, and then exposed to water the $d$-spacing expands to $16.5 \AA$, and this co-intercalation of water facilitates the eventual exfoliation ${ }^{68}$. Indeed, after washing multilayers etched with the $\mathrm{HCl} / \mathrm{LiF}$ mixture to a $\mathrm{pH}$ of $\sim 6$, spontaneous exfoliation is observed 56 . The yields can be increased with the help of sonication. Using the $\mathrm{HCl} / \mathrm{LiF}$ method, Lipatov et al. ${ }^{75}$ showed that increasing the initial molar ratio of $\mathrm{LiF}: \mathrm{Ti}_{3} \mathrm{AlC}_{2}$ from 5:1 to 7.5:1 resulted in an increase of the yield of exfoliation by hand shaking.

After exfoliation, colloidal nanosheet suspensions, if they are not to be used immediately, have to be stabilized to prevent their aggregation by using adequate solvents and/or surfactants. Arguably, one of the reasons MXenes have become so popular lately (more than 400 papers published in 2018 alone) has to be the ease by which water stable colloids near neutral pH can be produced. Note when the $\mathrm{pH}$ veers significantly from neutral, the suspensions are no longer stable $^{76,77}$. Maleski et al. studied the stabilities of exfoliated MXenes in various organic solvents, and showed that in general polar solvents are better at dispersing $\mathrm{Ti}_{3} \mathrm{C}_{2} \mathrm{~T}_{\mathrm{Z}}$ than non-polar ones ${ }^{78}$. As generally the case with colloids, exfoliated sheets are separated from their multilayers and any unreacted parent phase by centrifugation. Once a colloidal suspension of single or few sheets is obtained it can be processed in a variety of different ways (Figure $4 \mathrm{C}$ ): vacuum filtration to obtain thick films (typically a few microns) with orientated flakes ${ }^{70}$, crashed by the addition of an acid or a base to obtain an open crumpled morphology ${ }^{76}$, spray ${ }^{79}$ or spin coated ${ }^{80,81}$ to obtain thin films (below $100 \mathrm{~nm}$ ). Because the flakes are conductive it is also possible to form relatively thick films rapidly by electrophoretic deposition ${ }^{82}$. 

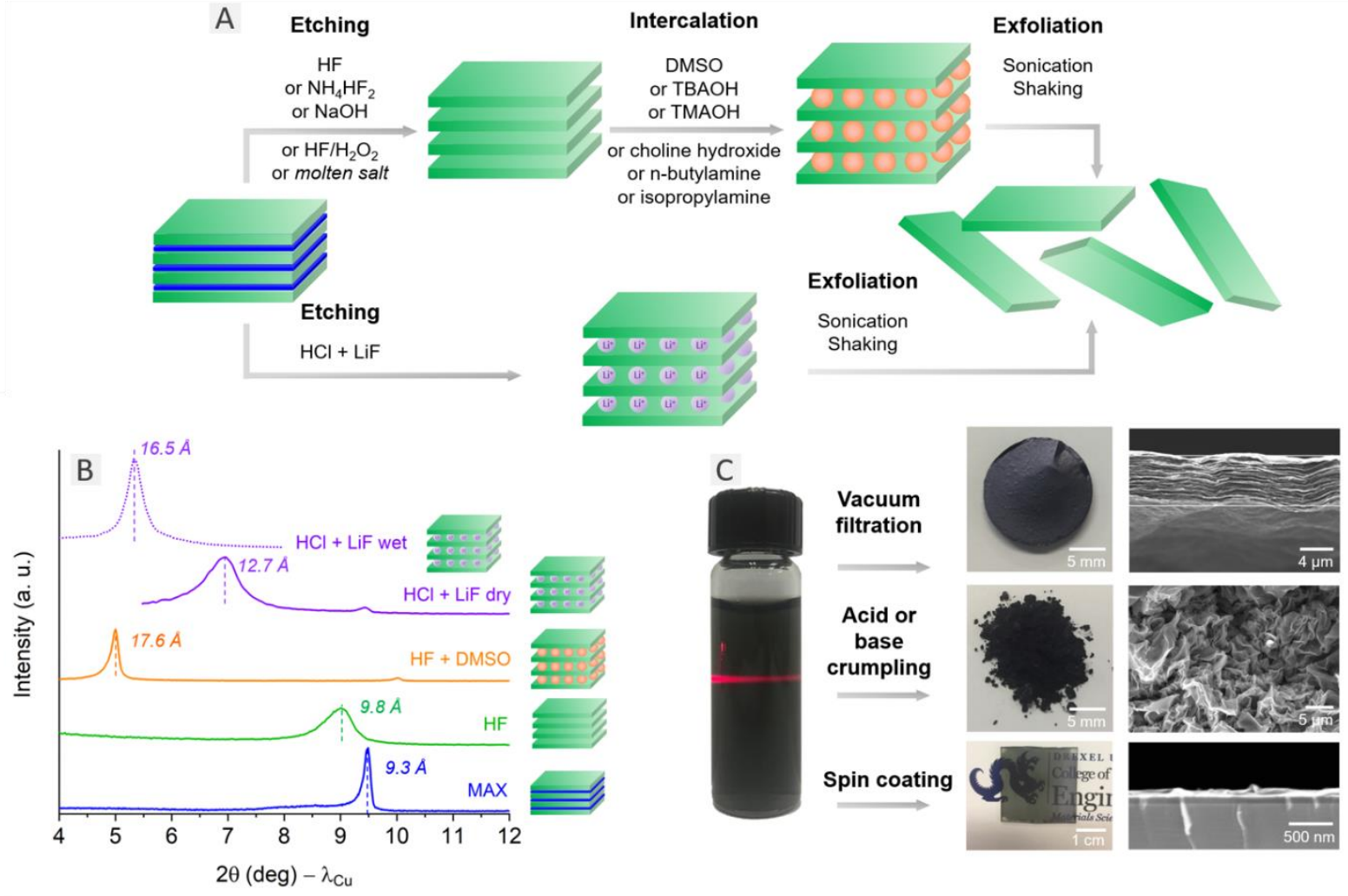

Figure 4: Exfoliation of multilayers MXenes into 2D nanosheets. (A) Schematic for MXenes exfoliation process depending on the etching process. (B) XRD patterns for $\mathrm{Ti}_{3} \mathrm{AlC}_{2} \mathrm{MAX}$ phase (blue), dry multilayers $\mathrm{Ti}_{3} \mathrm{C}_{2} \mathrm{~T}_{z}$ MXenes after etching with $\mathrm{HF}$ and washing (green) and after intercalation with DMSO (orange), dry (solid line purple) and wet (dotted line purple) multilayers $\mathrm{Ti}_{3} \mathrm{C}_{2} \mathrm{~T}_{z}$ MXenes etched with $\mathrm{HCl}+\mathrm{LiF}$. (C) Picture of a colloidal suspension of exfoliated MXenes showing the Tyndall effect and illustrations of processing the solution: digital photograph on the left and SEM images of (from top to bottom) vacuum filtered film (cross section for the SEM image), crumpling powder (adapted with permission from ${ }^{83}$ Copyright 2018 American Chemical Society) and spin-coated film (cross section for the SEM image adapted with permission from ${ }^{80}$, Wiley).

\subsection{MXene characteristics produced by top-down synthesis}

\subsubsection{Chemical order in MXenes}

As noted above, when the Al layers are etched from the $o$ - and $i$-MAX, the order is, for the most part, preserved. Density functional theory (DFT) calculations predicted the stability at 0 
$\mathrm{K}$ of 26 different type of MXenes derived from $o$-MAX phases ${ }^{42}$. For now, $\left(\mathrm{Cr}_{2 / 3} \mathrm{Ti}_{1 / 3}\right)_{3} \mathrm{C}_{2} \mathrm{~T}_{\mathrm{Z}}$, $\left(\mathrm{Mo}_{2 / 3} \mathrm{Ti}_{1 / 3}\right)_{3} \mathrm{C}_{2} \mathrm{~T}_{\mathrm{Z}}$ and $\left(\mathrm{Mo}_{1 / 2} \mathrm{Ti}_{1 / 2}\right)_{4} \mathrm{C}_{3} \mathrm{~T}_{\mathrm{Z}}$ were obtained from their parent $o$-MAX phases with $\mathrm{Ti}$ located in the inner layers ${ }^{42}$ (Figure 3), and also $\left(\mathrm{Mo}_{2 / 3} \mathrm{Sc}_{1 / 3}\right)_{3} \mathrm{C}_{2} \mathrm{~T}_{\mathrm{z}}{ }^{43}$. Not too surprisingly, the electrochemical properties of $\left(\mathrm{Mo}_{2 / 3} \mathrm{Ti}_{1 / 3}\right)_{3} \mathrm{C}_{2} \mathrm{~T}_{\mathrm{z}}$ are controlled by the outer Mo layer ${ }^{42}$. However, the inner layers also play an important role. For example, $\mathrm{Cr}_{2} \mathrm{CT}_{\mathrm{z}}$ MXenes has never been successfully synthesized because it tends to dissolve, but $\left(\mathrm{Cr}_{2 / 3} \mathrm{Ti}_{1 / 3}\right)_{3} \mathrm{C}_{2} \mathrm{~T}_{\mathrm{Z}}$ has. This implies that the inner $\mathrm{Ti}$ layer of $\left(\mathrm{Cr}_{2 / 3} \mathrm{Ti}_{1 / 3}\right)_{3} \mathrm{C}_{2} \mathrm{~T}_{\mathrm{z}}$ improves the overall stability of the $\mathrm{Cr}$ outer layer during etching.

The etching of the $i$-MAX phases can be tuned to either only etch the Al layers or both the $\mathrm{Al}$ and the minority $\mathrm{M}$ element (Figure 2). For example, etching both $\mathrm{Sc}$ and $\mathrm{Al}$ from $\left(\mathrm{Mo}_{2 / 3} \mathrm{Sc}_{1 / 3}\right)_{2} \mathrm{AlC}$, results in the formation of $\mathrm{Mo}_{1.33} \mathrm{CT}_{\mathrm{Z}}$ MXenes with ordered divacancies ${ }^{44}$. The same composition can also be obtained from $\left(\mathrm{Mo}_{2 / 3} \mathrm{Y}_{1 / 3}\right)_{2} \mathrm{AlC}$, when $\mathrm{Y}$ is etched together with $\mathrm{Al}$ ${ }^{49}$. Following the same method, $\mathrm{W}_{1.33} \mathrm{CT}_{\mathrm{Z}}$ was obtained from the $i$-MAX phases $\left(\mathrm{W}_{2 / 3} \mathrm{Sc}_{1 / 3}\right)_{2} \mathrm{AlC}$ and $\left(\mathrm{W}_{2 / 3} \mathrm{Y}_{1 / 3}\right)_{2} \mathrm{AlC}{ }^{46}$. These ordered divacancies influence MXene properties: for instance, $\mathrm{Mo}_{1.33} \mathrm{CT}_{\mathrm{Z}}$ exhibits a $65 \%$ higher volumetric capacitance than its counterpart with no vacancies, viz. $\mathrm{Mo}_{2} \mathrm{CT}_{\mathrm{z}}$. Interestingly, by controlling the etching conditions of $\left(\mathrm{Mo}_{2 / 3} \mathrm{Y}_{1 / 3}\right)_{2} \mathrm{AlC}$ powders, only the $\mathrm{Al}$ layer can be etched resulting in a MXene with in-plane ordering of the two transition metal elements ${ }^{49}$. In case of the $\left(\mathrm{Nb}_{2 / 3} \mathrm{Sc}_{1 / 3}\right)_{2} \mathrm{AlC}$ phase, there is no order. It follows that when both $\mathrm{Al}$ and $\mathrm{Sc}$ are etched, the resulting in MXenes has randomly distributed vacancies ${ }^{84}$.

\subsubsection{Surface chemistries}

As noted a few time, upon etching, the A layers - mostly Al - are replaced by surface terminations, mainly -OH, -O or -F groups ${ }^{85}$ (Figure $5 \mathrm{~A}$ ). Since some MXene properties depend on these terminations ${ }^{86}$, it is essential to know their nature and relative amounts. The multilayer terminations will depend on the: (i) etching method, (ii) nature of the $\mathrm{M}$ and $\mathrm{X}$ elements and, (iii) number of MX layers, or $\mathrm{n}$.

Quantitative nuclear magnetic resonance (NMR) spectroscopy has shown that multilayers $\mathrm{Ti}_{3} \mathrm{C}_{2} \mathrm{~T}_{\mathrm{z}}$ obtained by the HF etching method exhibit almost four times more - $\mathrm{F}$ terminations than ones etched in $\mathrm{HCl} / \mathrm{LiF}$ (Figure $5 \mathrm{~B}$ ) ${ }^{87}$. MXenes obtained by both methods have significantly fewer $-\mathrm{OH}$ terminations than $-\mathrm{F}$ and $-\mathrm{O}$. Kajiyama et al. claimed that $\mathrm{Ti}_{2} \mathrm{CT}_{\mathrm{z}} \mathrm{MXenes}$ etched 
using $\mathrm{HCl}+\mathrm{LiF}$ possibly have $-\mathrm{Cl}$ terminations, and further claimed that these terminations increase the $d$-spacing due to steric repulsion ${ }^{88}$. Recent work by Voigt et al. showed that $\operatorname{Ti}_{3} \mathrm{C}_{2} \mathrm{~T}_{\mathrm{z}}$ multilayers etched using a combination of $\mathrm{HF}+$ other acids - such as $\mathrm{HCl}, \mathrm{HBr}, \mathrm{HI}, \mathrm{H}_{3} \mathrm{PO}_{4}$ or $\mathrm{H}_{2} \mathrm{SO}_{4}$ - resulted in larger interlayer spacings than if they were not used, leading them to conclude that the anions of the mineral acids adsorb along the edges of the nanosheets, keeping the interlayer space open ${ }^{89}$.

Fluorine-free MXenes can be obtained by the hydrothermal treatment of $\mathrm{Ti}_{3} \mathrm{AlC}_{2}$ powders in $\mathrm{NaOH}^{90}$. The electrochemical etching of $\mathrm{Ti}_{2} \mathrm{AlC}$ in diluted $\mathrm{HCl}^{62}$ and $\mathrm{Ti}_{3} \mathrm{AlC}_{2}$ in a binary aqueous electrolyte $\left(\mathrm{NH}_{4} \mathrm{Cl}+\mathrm{TMAOH}\right){ }^{63}$ also yield MXenes without $\mathrm{F}$ terminations. To date no method has been published to synthesize MXenes terminated solely by F-terminations, or without any termination at all, the latter very unlikely except possibly under extreme reducing or vacuum conditions.

X-ray photoelectron spectroscopy (XPS) analysis on a wide range of MXenes multilayers $\left(\mathrm{Ti}_{2} \mathrm{CT}_{\mathrm{z}}, \mathrm{Ti}_{3} \mathrm{C}_{2} \mathrm{~T}_{\mathrm{z}}, \mathrm{Ti}_{3} \mathrm{CNT}_{\mathrm{z}}, \mathrm{Nb}_{2} \mathrm{CT}_{\mathrm{z}}\right.$ and $\left.\mathrm{Nb}_{4} \mathrm{C}_{3} \mathrm{~T}_{\mathrm{z}}\right)$ by Halim et al. showed that initially, after etching, most of the terminations are $-\mathrm{F}$, but with time are replaced by $-\mathrm{OH}^{85}$. In the case of the Ti-based MXenes changing $n$ from 1 to 2 or changing the $\mathrm{X}$ from $\mathrm{C}$ to $\mathrm{N}$ does not affect the quantity of $-\mathrm{F}$ terminations, but affects the $-\mathrm{OH}$ to $-\mathrm{O}$ termination ratio. Indeed, increasing $n$ from 1 to 2 induces an increase in the $-\mathrm{O}$ to $-\mathrm{OH}$ ratio. Replacing half of the $\mathrm{C}$ atoms with $\mathrm{N}$ leads to a decrease in the $-\mathrm{O}$ to $-\mathrm{OH}$ ratio. The trends observed in Ti-based MXenes are different than their $\mathrm{Nb}$-based counterparts. The amount of -F terminations is also affected by $n$ and the $-\mathrm{O}$ to $-\mathrm{OH}$ ratio decreases between $\mathrm{Nb}_{2} \mathrm{CT}_{\mathrm{z}}$ and $\mathrm{Nb}_{4} \mathrm{C}_{3} \mathrm{~T}_{\mathrm{z}}$ ( $n$ from 2 to 4$)^{85}$.

The MXene terminations can also be modified during the exfoliation process. For example, TBAOH, used for delaminating HF-etched MXenes, increases the -O terminations at the expense of $-\mathrm{F}^{91}$, indicating once again that the latter are thermodynamically unstable compared to -O. This was also observed when $\mathrm{K}^{+}$and DMSO were intercalated in the interlayer space prior to exfoliation ${ }^{86}$.

Post-synthesis of the MXene surface chemistry is also possible. For example, in situ heating, while collecting XPS spectra of $\mathrm{Ti}_{3} \mathrm{C}_{2} \mathrm{~T}_{\mathrm{Z}}$ thin films showed that the $-\mathrm{F}$ terminations start to desorb around $500{ }^{\circ} \mathrm{C}$ and are mostly desorbed by $750{ }^{\circ} \mathrm{C}{ }^{92}$ (Figure $5 \mathrm{C}$ ). Thermal annealing of $\mathrm{Ti}_{2} \mathrm{C}(\mathrm{OH})_{\mathrm{x}} \mathrm{F}_{\mathrm{y}}$ at $1100{ }^{\circ} \mathrm{C}$ also resulted in a loss of the $-\mathrm{F}$ terminations and the formation of 
$\mathrm{Ti}_{2} \mathrm{CO}_{\mathrm{x}}{ }^{93}$. The $-\mathrm{F}$ terminations on MXenes multilayers can also react with alkali hydroxides and are replaced by $-\mathrm{O}$ or $-\mathrm{OH}$ terminations ${ }^{94}$.
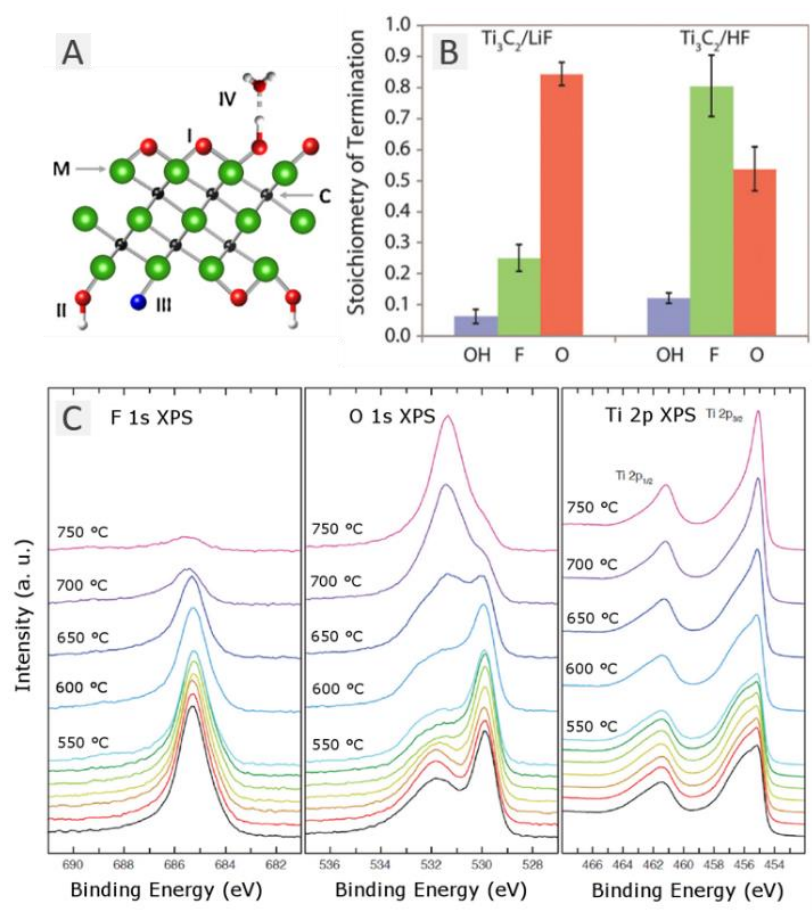

Figure 5: Terminations on $\boldsymbol{T i}_{3} \boldsymbol{C}_{2} \boldsymbol{T}_{z}$. (A) Schematic view of a $M_{3} X_{2} T_{z}$ MXene showing various terminations: I refers to a - $\mathrm{O}$ termination, II to - $\mathrm{OH}$, III to - $\mathrm{F}$ and $\mathrm{IV}$ to -OH strongly bond to an adsorbed $\mathrm{H}_{2} \mathrm{O}$ molecule. (B) Stoichiometry of surface functional groups on $\mathrm{Ti}_{3} \mathrm{C}_{2} \mathrm{~T}_{2}$ produced by etching $\mathrm{Ti}_{3} \mathrm{AlC}_{2}$ in HF or HCl/LiF solutions. (C) In situ XPS measurements revealing the temperature dependent behavior of (from left to right) $F 1 s, O 1 s$, and Ti $2 p$ with heating in vacuum. (A) is adapted with permission from ${ }^{78}$, Elsevier, $(B)$ is adapted with permission from ${ }^{87},(C)$ is adapted with permission from ${ }^{92}$.

\subsubsection{Defects}

Defects can originate from the parent 3D layered materials, during etching and/or exfoliation. Most of the studies done so far have focused on the influence of the etching and exfoliation methods. Not surprisingly, they show that milder conditions result in MXenes flakes with less defects ${ }^{33,59,75,95}$.

At the atomic scale, intrinsic defects have been observed in single or double layers of $\mathrm{Ti}_{3} \mathrm{C}_{2} \mathrm{~T}_{\mathrm{z}}$ by TEM. Figure $6 \mathrm{~A}$, shows metal adatoms and vacancies ${ }^{61,95}$, where in this case the Ti adatoms are positioned above other $\mathrm{Ti}$ atoms in the MXene lattice. Karlsson et al. ${ }^{61}$ suggested 
that $\mathrm{Ti}$ adatoms react with oxygen to form $\mathrm{TiO}_{\mathrm{x}}$ complexes. Modifying the etching method also has an impact on the metal vacancies. It was shown that increasing the HF concentration during etching results in an increase in the defect concentration ${ }^{95}$.

Defects at the macroscopic scale, such as pores, were observed in MXene single layers and also depend on the etching conditions. For instance, it was shown that shorter etching times resulted in less defective $\mathrm{Mo}_{2} \mathrm{CT}_{\mathrm{z}}$ flakes, but the MAX to MXenes conversion efficiency was lower ${ }^{33}$. Sonication during exfoliation can increase the yield, but the resulting flakes are more defective with a higher porosity as evidenced in $\mathrm{Mo}_{2} \mathrm{CT}_{\mathrm{z}}$ in Figure $6 \mathrm{~B}$, and are smaller as shown on $\mathrm{Ti}_{3} \mathrm{C}_{2} \mathrm{~T}_{\mathrm{z}}$ in Figure $6 \mathrm{C}$. When a milder method is used, such as hand-shaking, the flakes are bigger (Figure $6 \mathrm{C}$ ) ${ }^{33,75}$. Defects free single MXene layers have still not been reported to our knowledge.
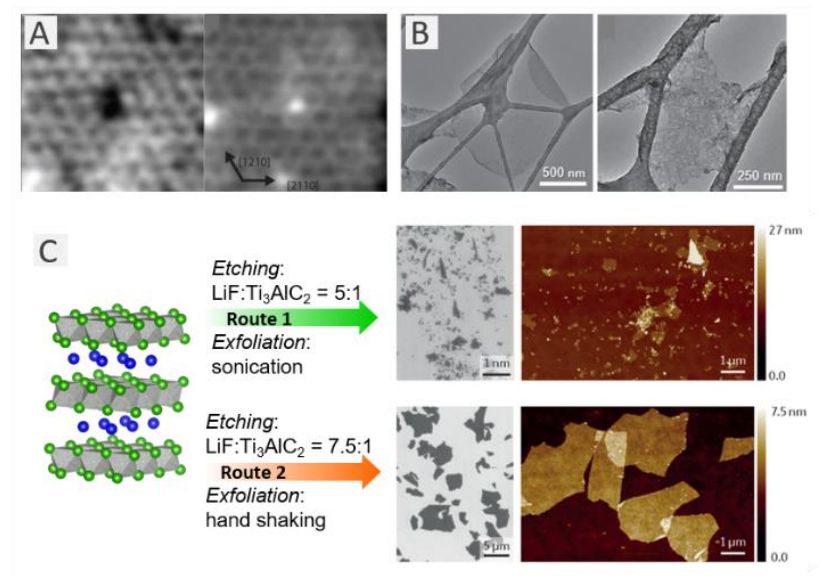

Figure 6: Defects in MXene single layers. (A) Atomic defects in $\mathrm{Ti}_{3} \mathrm{C}_{2} T_{z}$ : single Ti vacancy in a double sheet (left), Ti adatom on a single sheet (right). (B) $\mathrm{Mo}_{2} \mathrm{CT}_{z}$ sheets after etching in $\mathrm{HF}$, intercalation with TBAOH and delaminated by two methods: hand shaking for 5 min (left) or sonication during $1 \mathrm{~h}$ (right). (C) Synthesis of $\mathrm{Ti}_{3} \mathrm{C}_{2} \mathrm{~T}_{2}$ by two methods: route 1 with exfoliation by sonication leads to smaller flakes size, while route 2 with exfoliation by hand shaking gives larger flakes size. (A) is adapted with permission from ${ }^{61}$, Copyright 2015 American Chemical Society. (B) is adapted with permission from ${ }^{33}$, Wiley. $(C)$ is adapted with permission from ${ }^{17}$, Copyright 2017 Springer Nature. 


\section{Synthesis of 2D transition metal carbides and nitrides by bottom-up approaches}

As shown above, selective etching methods have been extensively used to synthesize MXenes. Recently, several bottom-up synthesis methods have also been developed including chemical vapor deposition (CVD) $)^{18,96,105-107,97-104}$, template method ${ }^{108-110}$ and plasma enhanced pulsed laser deposition (PEPLD) ${ }^{111,112}$. Compared to the selective etching process, the materials produced by the bottom-up methods, in particular CVD, have high crystalline quality. Moreover, these methods enable the synthesis of 2D transition metal carbides (TMCs) and nitrides (TMNs) with stoichiometries that cannot be obtained by selective etching, such as $\mathrm{WC}^{18,103}, \mathrm{TaC}^{18,98}$, $\mathrm{TaN}^{98}, \mathrm{MoN}^{108,109}$ and heterostructures ${ }^{100-105,107}$. It is important to note that neither single layers of TMCs or TMNs have been grown so far with these methods, but rather thin film comprised of a few layers. However, the thin films exhibit 2D properties, in terms of superconducting transitions for example ${ }^{18}$.

\subsection{CVD growth of 2D TMCs and TMNs}

In 2015, Xu et al. ${ }^{18}$ first reported the growth of high-quality ultrathin TMCs crystals by CVD, in which a bilayer metal foil (copper, $\mathrm{Cu} /$ transition metal) was used as a growth substrate. A schematic of the CVD growth process is shown in Figure $7 \mathrm{~A}^{113}$. The stack of $\mathrm{Cu} / \mathrm{Mo}$ foils was first heated to a temperature above $1085^{\circ} \mathrm{C}$ (Cu melting point) in hydrogen $\left(\mathrm{H}_{2}\right)$, and then a low flow rate of methane was introduced, resulting in the formation of $\mathrm{Mo}_{2} \mathrm{C}$ crystals on the liquid $\mathrm{Cu}$ surface. During the growth process, the top liquid $\mathrm{Cu}$ layer plays several important roles. On the one hand, it acts as catalyst to decompose methane into carbon atom. On the other hand, it works as a channel to control the diffusion of Mo atoms from the Mo foil to the liquid $\mathrm{Cu}$ surface. As a result, ultrathin $\mathrm{Mo}_{2} \mathrm{C}$ crystals are formed on the liquid $\mathrm{Cu}$ surface by the reaction of $\mathrm{C}$ and $\mathrm{Mo}$ atoms. In addition, after $\mathrm{Mo}_{2} \mathrm{C}$ growth, the $\mathrm{Cu}$ acts as a sacrificial layer that, in turn, enables the transfer of $\mathrm{Mo}_{2} \mathrm{C}$ to any target substrate by etching because of the large differences in chemical reactivity between $\mathrm{Cu}$ and $\mathrm{Mo}_{2} \mathrm{C}$.

Figure $7 \mathrm{~B}$ shows a typical ultrathin $\mathrm{Mo}_{2} \mathrm{C}$ crystals grown on a $\mathrm{Cu} / \mathrm{Mo}$ substrate. The latter appear in various regular shapes, mainly including triangles, rectangles, hexagons, octagons, nonagons and dodecagons. The thickness of most crystals can be controlled within 3$20 \mathrm{~nm}$. Importantly, the crystals can be transferred perfectly onto arbitrary target substrates by using $0.2 \mathrm{M}\left(\mathrm{NH}_{4}\right)_{2} \mathrm{~S}_{2} \mathrm{O}_{8}$ solution to etch the $\mathrm{Cu}$. Atomic force microscopy (AFM) images show 
that the $\mathrm{Mo}_{2} \mathrm{C}$ crystals have clean and smooth surfaces (Figure $7 \mathrm{C}$ ). Selective area electron diffraction (SAED) was used to show that the crystal structure was orthorhombic, $\alpha-\mathrm{Mo}_{2} \mathrm{C}$ (Figure 7 D). Different from MXenes, atomic-level high angle annular dark field (HAADF)scanning transmission electron microscope (STEM) measurements show that the as-obtained $\alpha$ $\mathrm{Mo}_{2} \mathrm{C}$ crystals have a high crystalline quality (Figure $7 \mathrm{E}$ ). These high-quality samples provide a good platform to study the intrinsic properties of TMCs near the 2D limit, such as 2D superconductivity ${ }^{18,114,115}$.

Further studies ${ }^{116}$ show that the Mo atom sub-lattice has uniform hexagonal closelypacked arrangement across the crystal without boundaries for all shaped crystals. However, except for the rectangular and octagonal crystals, the $\mathrm{C}$ atom sub-lattices are composed of three or six domains with rotational-symmetry and well-defined line-shaped domain boundaries because of the presence of three equivalent octahedron-off-center zigzag configurations of $\mathrm{C}$ atoms, as shown in Figure 7 F-I. These domain boundaries have been shown to have a strong influence on the 2D superconductivity. Moreover, the 2D $\alpha-\mathrm{Mo}_{2} \mathrm{C}$ crystals can be transformed into $\beta$ - $\mathrm{Mo}_{2} \mathrm{C}$ crystals under electron irradiation in a TEM ${ }^{117}$. Importantly, this CVD method is quite universal and can also be used to grow other high quality 2D TMC crystals such as ultrathin hexagonal WC (Figure $7 \mathrm{~J}$ and $\mathrm{K}$ ) and cubic TaC (Figure $7 \mathrm{~L}$ and $\mathrm{M}$ ). The latter are grown using $\mathrm{W}$ and Ta foils instead of Mo, respectively ${ }^{18}$.

Following this work, Geng et al. ${ }^{97}$ demonstrated structural control of the morphology of $\mathrm{Mo}_{2} \mathrm{C}$ crystals by changing the concentration of $\mathrm{CH}_{4}$. When a low flow rate of $\mathrm{CH}_{4}(0.1 \mathrm{sccm})$ was used, fractal $\mathrm{Mo}_{2} \mathrm{C}$ crystals were obtained. With increasing $\mathrm{CH}_{4}$ concentration, the shape of $\mathrm{Mo}_{2} \mathrm{C}$ crystals changed from triangular to other polygons, resulting from a higher $\mathrm{C}$ supersaturation. At $\mathrm{CH}_{4}$ flow rates of $0.3 \mathrm{sccm}, 0.4 \mathrm{sccm}$ and $0.6 \mathrm{sccm}$, the dominant shapes were rectangles, pentagons and hexagons, respectively. However, they found that the hexagonal $\mathrm{Mo}_{2} \mathrm{C}$ crystals have a hexagonal structure, which is different from the orthorhombic structure reported by $\mathrm{Xu}$ et al. ${ }^{18}$ Furthermore, they realized that the thickness of the $\mathrm{Mo}_{2} \mathrm{C}$ crystals can be controlled by changing the thickness of the $\mathrm{Cu}$ foil. Very recently, Chaitoglou et al. ${ }^{104}$ reported the growth of stacks of $\mathrm{Mo}_{2} \mathrm{C}$ crystals with a thickness of $\sim 2 \mathrm{~nm}$, which demonstrates the 2D limit of the $\mathrm{Mo}_{2} \mathrm{C}$ domains. 
Wang et al. ${ }^{98}$ demonstrated that the CVD method also can be used to grow various 2D Ta-compounds. Figure $7 \mathrm{~N}$ shows a schematic of the growth of ultrathin TaC crystals. Besides TaC, 2D TaN can be synthesized by using $\mathrm{NH}_{3}$ as a nitrogen source. Different from Xu el al.'s work, the $\mathrm{Cu}$ foil in this case, is kept in the solid state during the whole growth process, in which a temperature close to the melting point of $\mathrm{Cu}\left(1077^{\circ} \mathrm{C}\right)$ was used. Figure $7 \mathrm{O}$ shows a HR-TEM image of TaN and the inset shows the SAED pattern, which confirms that the as-obtained TaN is single crystalline and of a high crystalline quality. Ultrathin TaB crystals were also synthesized by changing $\mathrm{NH}_{3}$ to boron powder as the $\mathrm{B}$ source. They pointed out that the thickness of the $2 \mathrm{D}$ crystals can be more easily controlled at a temperature below the melting point of $\mathrm{Cu}$. Furthermore, they found that the lower temperatures were enough for supplying the excess energy of $0.03 \mathrm{eV}$ required for a $\mathrm{Ta}$ atom to diffuse into a vacant $\mathrm{Cu}$ lattice site by DFT calculations (for example, $k_{\mathrm{B}} \mathrm{T} \approx 129 \mathrm{meV}$ at $1356 \mathrm{~K}$ ).

Qi et al. ${ }^{99}$ reported a different CVD process to grow $\mathrm{ReC}$, which is a metastable carbide phase. They first grew graphene on Re (0001) at $903 \mathrm{~K}$. Subsequently, the grown graphene was annealed at 953-1113 $\mathrm{K}$ and decomposed to $\mathrm{C}$ atoms, which were then dissolved in the $\mathrm{Re}$ substrate. Finally, during the cooling process, monatomic layer $\mathrm{ReC}$ crystals with a periodic "flower-like" superstructure were formed through C segregation from the Re substrate. Unfortunately, the obtained $2 \mathrm{D} \mathrm{ReC}$ is difficult to separate from the Re growth substrate. 


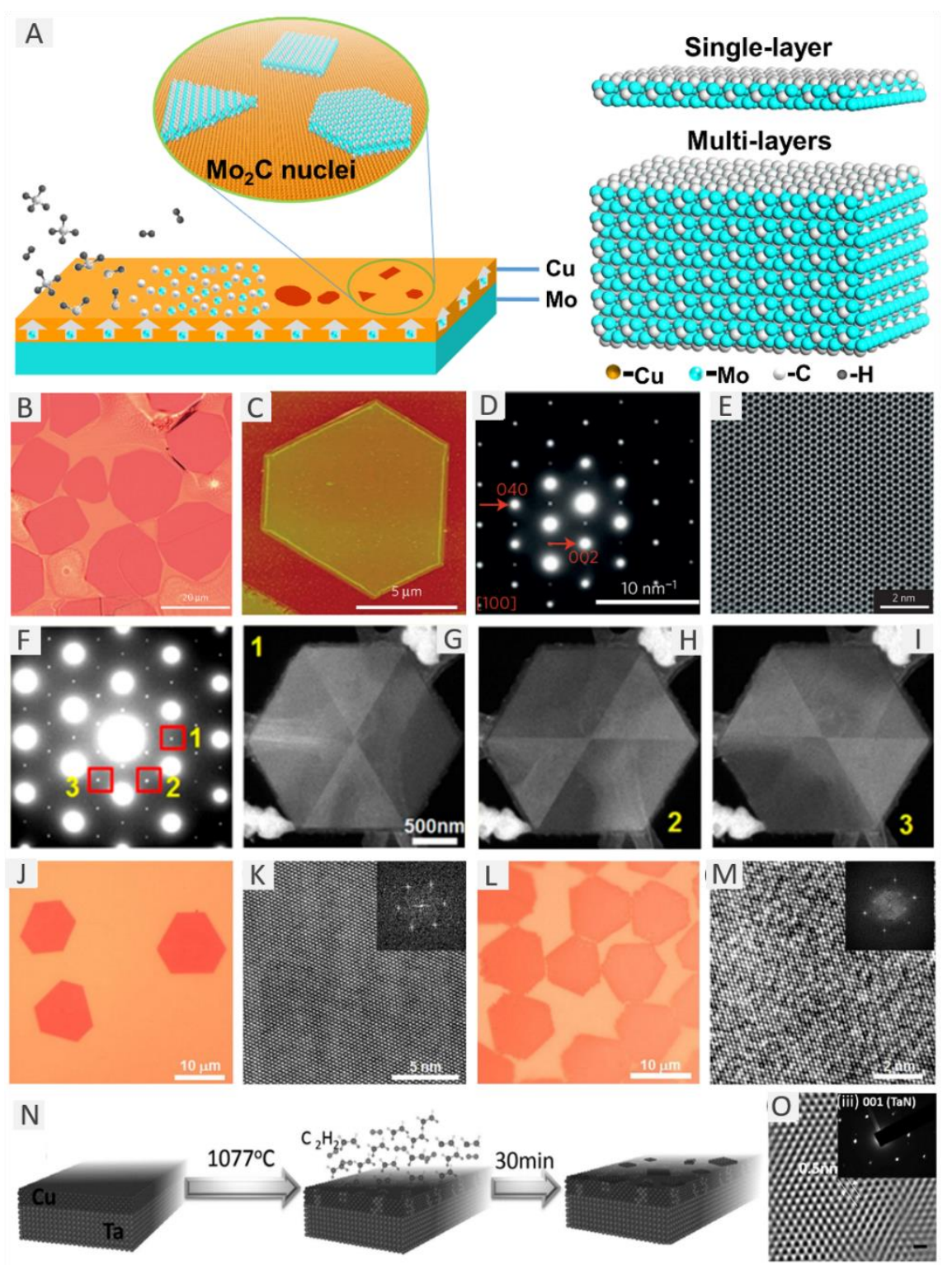

Figure 7: 2D TMCs and TMNs synthesized by CVD. (A) Schematic of the growth process and atomic models of 2D $\mathrm{Mo}_{2} \mathrm{C}$ crystals. (B) Optical image of $2 \mathrm{D} \alpha-\mathrm{Mo}_{2} \mathrm{C}$ crystals on Cu/Mo substrate. (C) AFM image of a $8.2 \mathrm{~nm}$-thick $\alpha$ $\mathrm{Mo}_{2} \mathrm{C}$ crystal transferred on $\mathrm{SiO}_{2} / \mathrm{Si}$ substrate. (D) SAED pattern of $\alpha-\mathrm{Mo}_{2} \mathrm{C}$ single crystal along [100]. (E) Atomiclevel HAADF-STEM image of $\alpha-\mathrm{Mo}_{2} \mathrm{C}$ crystal. (F) SAED pattern of an ultrathin hexagonal $\mathrm{Mo}_{2} \mathrm{C}$ crystal. (G-I) Dark-field TEM images obtained from the ED spots 1-3 in $(F)$ clearly showing the well-defined domain structure of the hexagonal $\mathrm{Mo}_{2} \mathrm{C}$ crystal. $(\mathrm{J}, \mathrm{K})$ Optical $(J)$ and HRTEM $(K)$ images of the $2 D$ ultrathin hexagonal WC crystals. $(L, M)$ Optical $(L)$ and HRTEM $(M)$ images of the 2D ultrathin cubic TaC crystals. (N) Schematic of the CVD growth of ultrathin $2 D$ TaC crystals. (O) HRTEM image of $2 D$ TaN crystal. The inset of $(O)$ is the SAED pattern along [001]. (A) is adapted with permission from ${ }^{113},(B-E, J-M)$ are adapted with permission from Springer Nature ${ }^{18}$ Copyright 2015, (F-I) are adapted with permission from ${ }^{116}$ Copyright 2016 American Chemical Society, (N, O) are adapted with permission from ${ }^{98}$ Copyright Wiley-VCH. 


\subsection{CVD growth of Heterostructures of 2D TMCs and Graphene}

In addition to 2D TMC and TMNs, CVD methods can also be used directly to synthesize vertical/in-plane heterostructures of graphene and 2D TMCs ${ }^{100-105,107}$. Two different synthesis approaches have been reported to grow $2 \mathrm{D} \mathrm{Mo}_{2} \mathrm{C} /$ graphene vertical heterostructures. Deng et al. reported the direct growth of such structures using one-step CVD, as shown in Figure 8 A-C ${ }^{107}$. Compared to the growth of pure $\mathrm{Mo}_{2} \mathrm{C}$ crystals, a higher concentration of $\mathrm{CH}_{4}$ was used to form graphene. The visible Raman D peak indicates the presence of defects in the graphene in the heterostructures which is possibly because of a competition between the growth of the $2 \mathrm{D} \mathrm{Mo}_{2} \mathrm{C}$ crystals and the graphene. The $2 \mathrm{D} \mathrm{Mo} 2 \mathrm{C}$ crystals are located on the top of the graphene layers. Qiao et al. ${ }^{101,105}$ also synthesized vertical heterostructures of $2 \mathrm{D} \mathrm{Mo}_{2} \mathrm{C}$ and graphene by a onestep CVD process and studied the interfacial orientational relationship between the $\mathrm{Mo}_{2} \mathrm{C}$ and graphene. A $11^{\circ}$ rotational angle was found between the two, as shown in Figure $8 \mathrm{D}{ }^{101}$. Moreover, a 2D spinodal interface was observed, which indicates that the interface in this onestep CVD grown heterostructure is not perfect (Figure 8 E) ${ }^{105}$. Different from Loh's work ${ }^{100}$, they found that the $2 \mathrm{D} \mathrm{Mo}_{2} \mathrm{C}$ is located on the bottom of the graphene layers in all their heterostructures synthesized by one-step CVD ${ }^{101,105,107}$.

$\mathrm{Xu}$ et al. ${ }^{102}$ developed a two-step CVD method to grow graphene/2D $\mathrm{Mo}_{2} \mathrm{C}$ vertical heterostructures, in which the $2 \mathrm{D} \mathrm{Mo}_{2} \mathrm{C}$ is located at the bottom of the graphene layer. As shown in Figure $8 \mathrm{~F}$, an intact graphene film was first grown on a solid $\mathrm{Cu}$ surface at temperature below the melting point of $\mathrm{Cu}$. Subsequently, the growth temperature was increased to above the melting point to grow $\mathrm{Mo}_{2} \mathrm{C}$ crystals underneath the graphene layer on the liquid $\mathrm{Cu}$ surface. Very interestingly, as shown in Figure $8 \mathrm{G}$ and $\mathrm{H}$, the graphene and $\mathrm{Mo}_{2} \mathrm{C}$ crystals are well aligned in lattice orientation in the heterostructures, suggesting epitaxial growth of $^{\mathrm{Mo}_{2} \mathrm{C} \text { on }}$ graphene. Similar to the pure $\mathrm{Mo}_{2} \mathrm{C}$ crystals alluded to above, the $\mathrm{Mo}_{2} \mathrm{C}$ crystals in the heterostructures have high crystalline quality. However, it was found that there is a considerable compression in the graphene in the heterostructure, as evidenced by the large Raman shift of both $\mathrm{G}$ and 2D peaks, revealing a strong coupling between graphene and $\mathrm{Mo}_{2} \mathrm{C}$. Raman maps of the heterostructure (Figure $8 \mathrm{~J}$-L) clearly show the presence of non-uniform strain domains, which results in unique superconductivity behavior that has not observed before in artificially 
stacked graphene/2D superconductor heterostructures. Chaitoglou et al. also confirmed the nonuniform stress in heterostructures by using Raman spectroscopy ${ }^{104}$.

Besides vertical heterostructures, 2D in-plane TMC-graphene (i-WC-G) heterostructure can also be synthesized by a similar CVD process. Zeng et al. ${ }^{103}$ synthesized 2D in-plane WCgraphene heterostructures at $980-1020^{\circ} \mathrm{C}$, using a substrate of a Ga droplet sitting on the top of a $\mathrm{W}$ foil (Figure $8 \mathrm{M}$ ). They explained that $\mathrm{Ga}$, as a low melting point metal, provides the possibility for co-segregation of $\mathrm{W}$ and $\mathrm{C}$ atoms to form in-plane $\mathrm{WC}$-graphene heterostructure. As shown in Figure $8 \mathrm{~N}, 2 \mathrm{D}$ WC crystals were uniformly embedded in graphene film. The coverage percentage of WC can be controlled from $40 \%$ to $95 \%$ by changing the growth parameters, including growth temperature and growth time. The WC crystals also have a high quality and a typical hexagonal crystalline structure (Figure 8 O). Moreover, based on AFM measurements they were $\sim 1.36 \mathrm{~nm}$ thick (Figure $8 \mathrm{P}$ ). 


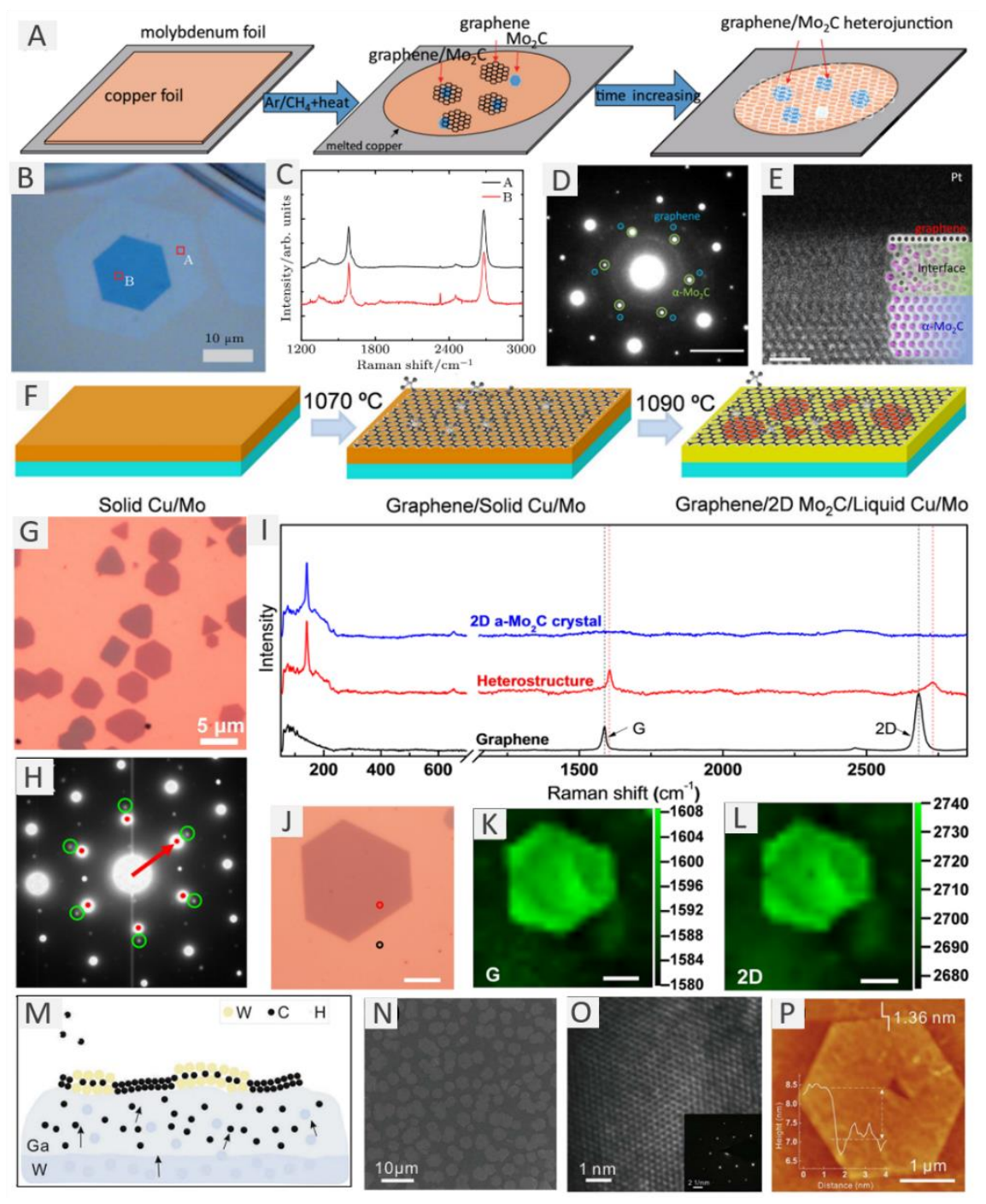

Figure 8: The heterostructures of 2D TMCs and graphene synthesized by CVD. (A) Schematic of one-step CVD growth of $2 \mathrm{D} \alpha-\mathrm{Mo}_{2} \mathrm{Clgraphene} \mathrm{vertical} \mathrm{heterostructures.} \mathrm{(B)} \mathrm{Optical} \mathrm{image} \mathrm{of} \mathrm{a} \mathrm{hexagonal} 2 \mathrm{D} \alpha-\mathrm{Mo}_{2} \mathrm{C} / \mathrm{graphene}$ heterostructure on $\mathrm{Cu} / \mathrm{Mo}$ substrate. $(C)$ Raman spectra of the graphene taken from the $A$ and $B$ areas in (b). (D) $S A E D$ pattern of $2 \mathrm{D} \alpha-\mathrm{Mo}_{2} \mathrm{C} /$ graphene heterostructure, in which the ED spots related to graphene and $\alpha-\mathrm{Mo}_{2} \mathrm{C}$ are marked by blue and green circles, respectively. The scale bar is $5 \mathrm{~nm}^{-1}$. (E) HRTEM image of the cross section of 2D $\mathrm{Mo}_{2} \mathrm{C} /$ graphene heterostructure. (F) Schematic of the two-step CVD growth process of graphene/2D $\alpha-\mathrm{Mo}_{2} \mathrm{C}$ vertical heterostructure. $(G)$ Optical image of graphene/ $2 \mathrm{D} \alpha-\mathrm{Mo}_{2} \mathrm{C}$ heterostructures on growth substrate. $(H)$ SAED pattern of a graphene $2 \mathrm{D} \alpha-\mathrm{Mo}_{2} \mathrm{C}$ crystal heterostructure, in which the ED spots related to graphene and $\alpha$ $\mathrm{Mo}_{2} \mathrm{C}$ are marked by green circles and red spots, respectively. I) Raman spectra of a pure $2 \mathrm{D} \alpha-\mathrm{Mo}_{2} \mathrm{C}$ crystal, the heterostructure denoted by red circle in $(J)$ and the pure graphene denoted by black circle. $(J-L)$ Optical image $(J)$ of a graphene/hexagonal $2 \mathrm{D} \alpha-\mathrm{Mo}_{2} \mathrm{C}$ heterostructure, and the corresponding $G(K)$ and $2 D$ peak $(L)$ position maps. The scale bars are $5 \mu \mathrm{m}$. (M) Schematic of a Ga/W bilayer substrate for CVD growth of 2D $i$-WC-G. (N) SEM image of ultrathin WC crystals embedded in graphene film. (O) HRTEM image of $2 D$ WC crystal. (P) AFM image of a $2 D$ hexagonal WC crystal with a thickness of $1.36 \mathrm{~nm}$. (A-C) are adapted with permission from ${ }^{107},(D)$ is adapted with 
permission from ${ }^{101}$ Copyright 2017 American Physical Society, (E) is adapted with permission from ${ }^{105}$ Copyright 2018 American Physical Society, (F-L) are adapted with permission from ${ }^{102}$ Copyright 2017 American Chemical Society, (M-P) are adapted with permission from ${ }^{103}$ Copyright 2017 Elsevier.

\subsection{Template Methods for the Synthesis of 2D TMCs and TMNs}

In addition to CVD, template methods have also been developed for synthesizing 2D TMCs and TMNs ${ }^{108-110}$. Compared to CVD methods, the template method has much higher yields. All the template methods use 2D transition metal oxides (TMOs) nanosheets as templates, and these TMOs nanosheets were subsequently carbonized, or nitrided to synthesize 2D TMCs or TMNs. The structure of the 2D TMCs and TMNs depends on the 2D TMO used. Xiao et al. ${ }^{108}$ synthesized 2D $h$-MoN nanosheets by using 2D $\mathrm{MoO}_{3}$ nanosheets as templates, which were obtained by annealing a Mo-precursor covering $\mathrm{NaCl}$ crystals. Figure $9 \mathrm{~A}$ shows the schematic diagram of the synthesis process of 2D MoN. XRD patterns indicate that the 2D MoN obtained has a hexagonal structure, with lattice constants $\boldsymbol{a}=\boldsymbol{b}=5.75 \AA$ and $\boldsymbol{c}=5.62 \AA$ (Figure 9 B). Like MXene synthesized by selectively etching MAX phase, 2D MoN nnaosheets can be readily dispersed in water, with the Tyndall effect being clearly observed (inset in Figure 9 B). The obtained 2D MoN nanosheets are very uniform (Figure $9 \mathrm{C}$ ) with a thickness of $\sim 0.71 \mathrm{~nm}$ (Figure 9 D). 2D WN and VN nanosheets were synthesized by this method as well.

Chakrapani et al. ${ }^{109}$ also synthesized 2D hexagonal MoN nanosheets by the template method, in which 2D $\mathrm{MoO}_{3}$ nanosheets were vertically grown on a substrate by using a hot Mo filament reacting with $\mathrm{O}_{2}$ as template. As shown in Figure $9 \mathrm{E}$, the $2 \mathrm{D} \mathrm{MoO}_{3}$ nanosheets were transformed to $2 \mathrm{D}$ MoN nanosheets by heating in $\mathrm{NH}_{3}$ at $800{ }^{\circ} \mathrm{C}$, which completely copied the morphology of $\mathrm{MoO}_{3}$ nanosheets, standing on substrate vertically as well (Figure 9 E). A layered-like structure was observed in the obtained 2D MoN nanosheets (Figure $9 \mathrm{~F}$ ). These nanosheets have a lateral size of 20-30 $\mu \mathrm{m}$ and are 5-40 $\mathrm{nm}$ in thickness, which is much thicker than those synthesized byXiao et al. XRD analyses show that the samples are $\delta$-MoN.

Besides $\mathrm{MoO}_{3}$ nanosheets, $\mathrm{MoO}_{2}$ nanosheets can also be used as template to synthesize 2D TMCs. Recently, Zhou et al. ${ }^{110}$ synthesized ultrathin $\mathrm{N}$-doped $\mathrm{Mo}_{2} \mathrm{C}$ nanosheets, using $\mathrm{MoO}_{2}$ nanosheets as a template and dicyandiamide - as $\mathrm{C}$ and $\mathrm{N}_{2}$ source - be heating at $450{ }^{\circ} \mathrm{C}$ for $2 \mathrm{~h}$ and subsequently $700{ }^{\circ} \mathrm{C}$ for $2 \mathrm{~h}$. The $\mathrm{MoO}_{2}$ nanosheets are hexagonal sinnhape, which 
was obtained by heating commercial $\mathrm{MoO}_{3}$ powders at $900{ }^{\circ} \mathrm{C}$ in $\mathrm{Ar} / \mathrm{N}_{2}$ (9:1) mixture. Many nanopores were observed on the $\mathrm{N}$-doped $\mathrm{Mo}_{2} \mathrm{C}$ nanosheets, which indicate a low crystalline quality (Figure $9 \mathrm{G}$ ). A hexagonal structure was confirmed by the SAED pattern and Fourier transform (Figure $9 \mathrm{H}$ and I). From the EDS maps, $\mathrm{N}$ is distributed uniformly across the whole nanosheet (Figure $9 \mathrm{~J}$ and $\mathrm{K}$ ). They also synthesized pure $\mathrm{Mo}_{2} \mathrm{C}$ nanosheets by using glucose instead of dicyandiamide in the above approach.

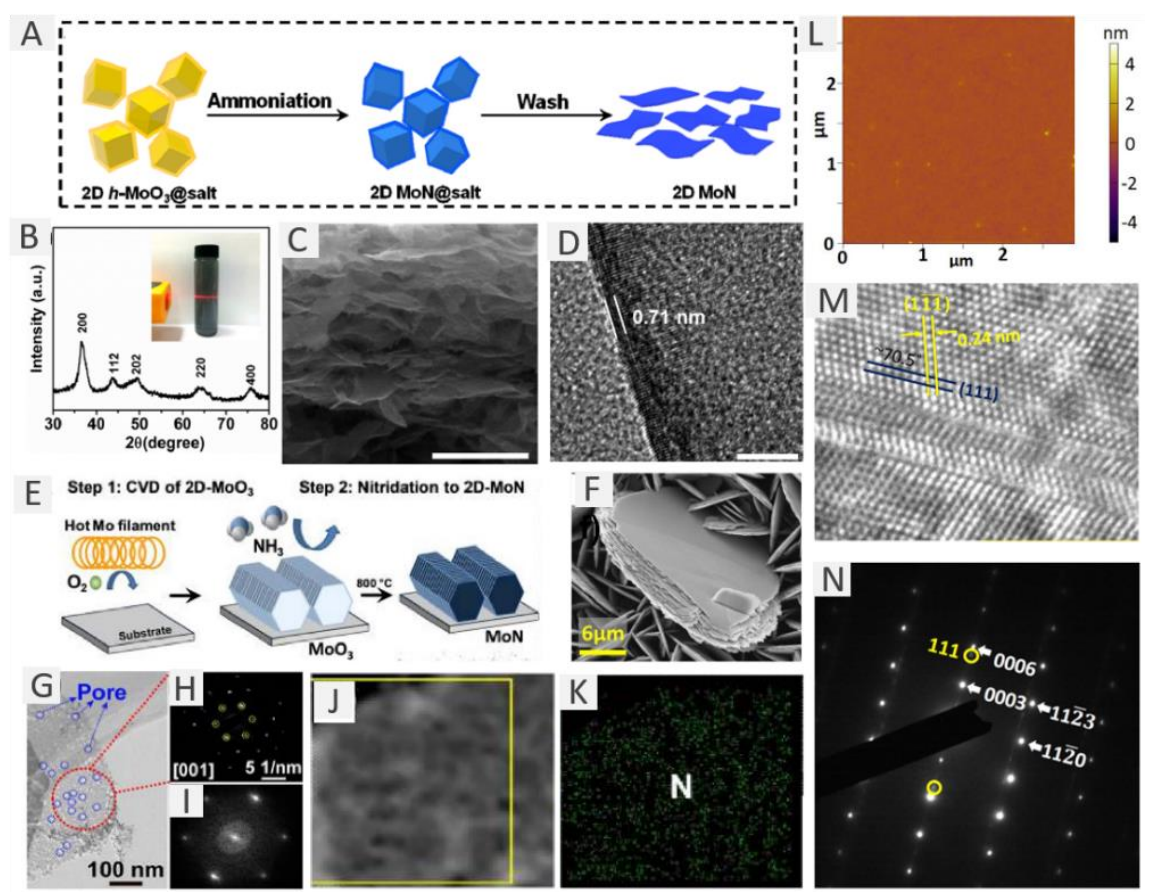

Figure 9: 2D MoN and N-doped-Mor $\mathrm{C}_{2}$ synthesized by template methods. (A) Schematic of the salt-assisted template synthesis process of ultrathin MoN nanosheets. (B) XRD pattern of 2D MoN nanosheets. Inset shows the Tyndall effect of the 2D MoN colloidal dispersion in water. (C) SEM image of 2D MoN nanosheets. Scale bar is 500 nm. (D) HRTEM image of the edge of an ultrathin MoN nanosheet. Scale bar is $5 \mathrm{~nm}$. (E) Schematic representation of template synthesis process of $2 D$ layers of $\delta-M o N$. (F) Top-view SEM image of vertically aligned $2 D$ layers of $\delta$ MoN on FTO. (G-I) TEM image (G), the corresponding ED pattern (H) and fast Fourier transform (I) of $\mathrm{N}-\mathrm{Mo}_{2} \mathrm{C}$ nanosheets. $(J, K)$ SEM image $(J)$ and the corresponding EDS mapping $(K)$ of ultrathin MoN nanosheet. $(L)$ AFM image of the as-grown $\mathrm{Mo}_{2} \mathrm{C}$ thin film. (M) Enlarged cross-sectional TEM image. Inset shows a low magnification TEM image of $\mathrm{Mo}_{2} \mathrm{C}$ film grown on a sapphire substrate. (N) SAED pattern taken from the cross section of the $\mathrm{Mo}_{2} \mathrm{C}$ film grown at $700{ }^{\circ} \mathrm{C}$. (A-D), (E-F), (G-J) are adapted with permission from ${ }^{108},{ }^{109}, 110$ respectively, Copyright 2017 American Chemical Society, (L-N) are adapted with permission from ${ }^{111}$ Copyright 2017 American Physical Society.

\subsection{PEPLD Methods for the Synthesis of 2D TMCs}


Recently, Zhang et al. ${ }^{111,112}$ developed a PEPLD method to synthesize large-area ultrathin, FCC $\mathrm{Mo}_{2} \mathrm{C}$ films on sapphire (0001). This approach combines the advantages of both plasma enhanced chemical vapor deposition and pulsed laser deposition. In this synthesis process, the sapphire substrate was heated to $700{ }^{\circ} \mathrm{C}$ for the deposition of high quality $\mathrm{Mo}_{2} \mathrm{C}$ film, using $\mathrm{CH}_{4}$ plasma as a $\mathrm{C}$ source reacted with the Mo vapor generated by the pulsed laser. They found that $\mathrm{CH}_{4}$ plasma favors the formation of $\mathrm{Mo}_{2} \mathrm{C}$. The as-obtained $\mathrm{FCC} \mathrm{Mo}_{2} \mathrm{C}$ film is quite uniform and smooth, as shown in Figure $9 \mathrm{~L}$ and can be controlled within 2-25 nm by changing the laser pulse rate. However, the films obtained have much lower crystalline quality than the CVD-grown samples, and a large number of stacking faults were observed in cross sectional TEM images (Figure $9 \mathrm{M}$ ). They suggested that the formation of the FCC structure unlike other crystal structures originates from an orientation relationship and little lattice mismatch between $\{111\}_{\text {Mo2 C }}$ and $\{0003\}_{\text {sapphire }}$ (Figure $9 \mathrm{~N}$ ).

\section{Conclusion}

Currently about 30 different MXene compositions have been synthesized by top-down approaches and theoretical studies predict the stability of many more. New MXenes are being discovered regularly, as well as new etching methods. Ironically, this embarrassment of richness poses somewhat of a dilemma. To date, and as this review attests, the vast majority of MXene papers have been on the first MXene discovered, viz. $\mathrm{Ti}_{3} \mathrm{C}_{2} \mathrm{~T}_{\mathrm{z}}$. And while this composition has already shown great promise in a large number of applications, there is no reason to believe it is the best for all applications. There is therefore an urgent need to bring our understanding of other compositions to the same level as $\mathrm{Ti}_{3} \mathrm{C}_{2} \mathrm{~T}_{\mathrm{z}}$. This is a non-trivial exercise given the large number of compositions and possible termination permutations, defects, etc. This is made even more urgent by the fact that even for $\mathrm{Ti}_{3} \mathrm{C}_{2} \mathrm{~T}_{\mathrm{z}}$ there is a lot more we do not understand than we understand.

The most efficient way to obtain this wide variety of MXenes is to use HF for now. An important challenge is to develop etching protocols without HF not only because of its toxicity, but also because the MXenes produced using HF contain -F terminations which are problematic for some applications, especially in the biomedical field. Even if -F terminations are reported to 
be less stable than $-\mathrm{O}$ and $-\mathrm{OH}$, there has been no report so far for their simple conversion post synthesis.

The discovery that $\mathrm{LiF} / \mathrm{HCl}$ mixtures etched $\mathrm{Ti}_{3} \mathrm{AlC}_{2}$ was an important breakthrough since for the most part it eliminated the direct use of HF. However, HF is still produced in-situ, and is present in the resulting etching solutions, and needs to be washed and processed. Li et al. 90 were the first to show that it is possible to etch $\mathrm{Ti}_{3} \mathrm{AlC}_{2}$ hydrothermally without fluoride ions, but the requisite conditions $\left(270{ }^{\circ} \mathrm{C}\right.$ in an autoclave) are quite harsh, not scalable and the properties of the resulting flakes have yet to be thoroughly investigated. The approach taken by Sun et al. ${ }^{62}$ in which porous MAX preforms were electrochemically etched in $\mathrm{HCl}$ is worth noting here. However, at this time, the yields of this method are quite low and the process quite slow indeed. A promising method is very recent work published by Yang et al. ${ }^{63}$ : they not only converted $\mathrm{Ti}_{3} \mathrm{AlC}_{2}$ in $\mathrm{Ti}_{3} \mathrm{C}_{2} \mathrm{~T}_{\mathrm{z}}$ electrochemically in a F-free electrolyte with yields higher than 40 $\%$, but also showed comparable performances in supercapacitors of the resulting MXenes to those obtained using the classical $\mathrm{HF}$ or $\mathrm{HCl} / \mathrm{LiF}$ methods.

The timing of the discoveries of the $i$-MAX and $o$-MAX phases could not have been better vis-à-vis greatly expanding MXene's chemical and structural space. It is worth noting that these phases, especially the $i$-MAX phases and their MXenes are still in their infancy and it is reasonable to assume that many more "ordered" MXenes will be discovered in the near future. The same is true of the $o$-MAX phases: DFT calculations predict the existence of 26 MXenes derivable from these phase ${ }^{42}$. Only a small fraction of their parent MAX phases has been synthesized. Discovering these phases, converting them to their MXenes, characterizing them and matching them with the myriad applications is a daunting, but exciting proposition. The same is true for the $i$-MAX phases. The importance of the latter lies in the possibility of introducing non-traditional $\mathrm{M}$ elements into the mix. The original $\mathrm{M}$ elements - discovered by Nowotny - were: Ti, V, Cr, Zr, Nb, Mo, Hf and Ta. Interestingly before 2014, only one Mocontaining MAX phase was known, today there are five.

As noted in the introduction the MXene discovery was paradigm shifting, because it showed the $3 \mathrm{D}$ to $2 \mathrm{D}$ transformation is not only restricted to relatively weakly bonded layered solids. For example, Zhou et al. have shown that it is possible to etch layered solids that are not MAX phases ${ }^{34,35}$. By etching $\mathrm{Al}_{3} \mathrm{C}_{3}$ and $(\mathrm{Al}, \mathrm{Si})_{4} \mathrm{C}_{4}$ from $\mathrm{Zr}_{3} \mathrm{Al}_{3} \mathrm{C}_{5}$ and $\mathrm{Hf}_{3}(\mathrm{Al}, \mathrm{Si})_{4} \mathrm{C}_{6}$, respectively, they produced the first Hf and Zr-based MXenes. 
Besides the well-known selective etching method, several bottom-up synthesis methods have been developed to synthesize 2D TMCs and TMNs. The CVD method, with bilayer metal foils as substrate, not only enables the growth of large-area, high-quality materials but also greatly expands the family of 2D TMCs and TMNs. Various 2D TMCs and TMNs, including MX-type (WC, TaC and TaN), non-hexagonal $\mathrm{M}_{2} \mathrm{X}$-type $\left(\alpha-\mathrm{Mo}_{2} \mathrm{C}\right.$, fcc-Mo $\left.\mathrm{M}_{2} \mathrm{C}\right)$ and hexagonal $\mathrm{M}_{2} \mathrm{X}$-type $\left(\beta-\mathrm{Mo}_{2} \mathrm{C}\right)$ have been synthesized by CVD. Moreover, the CVD process is also an effective method for the growth of vertical and in-plane heterostructures of 2D TMCs and graphene. The template method shows great potential to synthesize uniform atomically thin nanosheets at a large scale. The PEPLD method can also be used to grow large-area films. However, there are still many issues and challenges needed to be addressed for these bottom-up methods. For example, synthesizing large-area, high-quality atomically thin uniform 2D TMCs and TMNs film by CVD still remains a great challenge, and the materials synthesized by template and PEPLD methods have visible defects.

\section{Acknowledgments}

The authors thank Pieralberto Collini, Joseph Halim and Michael Ghidiu for providing the SEM and TEM images, respectively, and Sankalp Kota for fruitful discussions. C. Xu, H-M. Cheng and W. Ren acknowledge the National Science Foundation of China (Nos. 51325205, 51290273, and 51521091), the Chinese Academy of Sciences (No. KGZD-EW-T06), the Strategic Priority Research Program of Chinese Academy of Sciences (XDB30000000), SYNL-T.S. K Research Fellowship, and the Youth Innovation Promotion Association of Chinese Academy of Sciences.

\section{References:}

1. Nicolosi, V., Chhowalla, M., Kanatzidis, M. G., Strano, M. S. \& Coleman, J. N. Liquid Exfoliation of Layered Materials. Science 340, 1226419-1226419 (2013).

2. Novoselov, K. S. et al. Electric field effect in atomically thin carbon films. Science 306, 666-9 (2004).

3. Golberg, D. et al. Boron Nitride Nanotubes and Nanosheets. ACS Nano 4, 2979-2993 (2010). 
4. Wang, Q. H., Kalantar-Zadeh, K., Kis, A., Coleman, J. N. \& Strano, M. S. Electronics and optoelectronics of two-dimensional transition metal dichalcogenides. Nat. Nanotechnol. 7, 699-712 (2012).

5. Coleman, C. C., Goldwhite, H. \& Tikkanen, W. A Review of Intercalation in Heavy Metal Iodides. Chemistry of Materials 10, 2794-2800 (1998).

6. Ma, R. \& Sasaki, T. Nanosheets of Oxides and Hydroxides: Ultimate 2D Charge-Bearing Functional Crystallites. Adv. Mater. 22, 5082-5104 (2010).

7. Naguib, M. et al. Two-Dimensional Transition Metal Carbides. ACS Nano 6, 1322-1331 (2012).

8. Naguib, M. et al. Two-Dimensional Nanocrystals Produced by Exfoliation of $\mathrm{Ti}_{3} \mathrm{AlC}_{2}$. Adv. Mater. 23, 4248-4253 (2011).

9. Barsoum, M. W. Wiley: MAX Phases: Properties of Machinable Ternary Carbides and Nitrides - Michel W. Barsoum. 421

10. Naguib, M. et al. MXene: A promising transition metal carbide anode for lithium-ion batteries. Electrochem. commun. 16, 61-64 (2012).

11. Lukatskaya, M. R. et al. Cation intercalation and high volumetric capacitance of twodimensional titanium carbide. Science 341, 1502-5 (2013).

12. Ling, Z. et al. Flexible and conductive MXene films and nanocomposites with high capacitance. Proc. Natl. Acad. Sci. U. S. A. 111, 16676-81 (2014).

13. Han, M. et al. $\mathrm{Ti}_{3} \mathrm{C}_{2}$ MXenes with Modified Surface for High-Performance Electromagnetic Absorption and Shielding in the X-Band. ACS Appl. Mater. Interfaces $\mathbf{8}$, 21011-21019 (2016).

14. Shahzad, F. et al. Electromagnetic interference shielding with 2D transition metal carbides (MXenes). Science 353, 1137-40 (2016).

15. Peng, Q. et al. Unique Lead Adsorption Behavior of Activated Hydroxyl Group in TwoDimensional Titanium Carbide. J. Am. Chem. Soc. 136, 4113-4116 (2014).

16. Liu, H. et al. A novel nitrite biosensor based on the direct electrochemistry of hemoglobin 
immobilized on MXene-Tii $\mathrm{C}_{2}$. Sensors Actuators B Chem. 218, 60-66 (2015).

17. Anasori, B., Lukatskaya, M. R. \& Gogotsi, Y. 2D metal carbides and nitrides (MXenes) for energy storage. Nat. Rev. Mater. 2, 16098 (2017).

18. Xu, C. et al. Large-area high-quality 2D ultrathin $\mathrm{Mo}_{2} \mathrm{C}$ superconducting crystals. Nat. Mater. 14, 1135-1141 (2015).

19. Reina, A. et al. Large Area, Few-Layer Graphene Films on Arbitrary Substrates by Chemical Vapor Deposition. Nano Lett. 9, 30-35 (2009).

20. Wang, X., Feng, H., Wu, Y. \& Jiao, L. Controlled Synthesis of Highly Crystalline MoS 2 Flakes by Chemical Vapor Deposition. J. Am. Chem. Soc. 135, 5304-5307 (2013).

21. Dreyer, D. R., Park, S., Bielawski, C. W. \& Ruoff, R. S. The chemistry of graphene oxide. Chem. Soc. Rev. 39, 228-240 (2010).

22. Joensen, P., Frindt, R. F. \& Morrison, S. R. Single-layer MoS2. Mater. Res. Bull. 21, 457461 (1986).

23. Walker, G. F. \& Garrett, W. G. Chemical exfoliation of vermiculite and the production of colloidal dispersions. Science 156, 385-7 (1967).

24. Liu, Z. H., Ooi, K., Kanoh, H., Tang, W. P. \& Tomida, T. Swelling and delamination behaviors of birnessite-type manganese oxide by intercalation of tetraalkylammonium ions. Langmuir 16, 4154-4164 (2000).

25. Hernandez, Y. et al. High-yield production of graphene by liquid-phase exfoliation of graphite. Nat. Nanotechnol. 3, 563-568 (2008).

26. Pang, J. et al. Applications of 2D MXenes in energy conversion and storage systems. Chem. Soc. Rev. (2018).

27. Xiao, Y., Hwang, J.-Y. \& Sun, Y.-K. Transition metal carbide-based materials: synthesis and applications in electrochemical energy storage. J. Mater. Chem. A 4, 10379-10393 (2016).

28. Eklund, P., Rosen, J. \& Persson, P. O. A. Layered ternary $\mathrm{M}_{n+1} \mathrm{AX}$ n phases and their 2D derivative MXene: an overview from a thin-film perspective. J. Phys. D. Appl. Phys. 50, 
113001 (2017).

29. Hantanasirisakul, K. \& Gogotsi, Y. Electronic and Optical Properties of 2D Transition Metal Carbides and Nitrides (MXenes). Adv. Mater. 30, 1804779 (2018).

30. Hong Ng, V. M. et al. Recent progress in layered transition metal carbides and/or nitrides (MXenes) and their composites: synthesis and applications. J. Mater. Chem. A 5, 30393068 (2017).

31. Alhabeb, M. et al. Selective Etching of Silicon from $\mathrm{Ti}_{3} \mathrm{SiC}_{2}$ (MAX) To Obtain 2D Titanium Carbide (MXene). Angew. Chemie - Int. Ed. 57, 5444-5448 (2018).

32. Meshkian, R. et al. Synthesis of two-dimensional molybdenum carbide, $\mathrm{Mo}_{2} \mathrm{C}$, from the gallium based atomic laminate $\mathrm{Mo}_{2} \mathrm{Ga}_{2}$ C. Scr. Mater. 108, 147-150 (2015).

33. Halim, J. et al. Synthesis and Characterization of 2D Molybdenum Carbide (MXene). Adv. Funct. Mater. 26, 3118-3127 (2016).

34. Zhou, J. et al. A Two-Dimensional Zirconium Carbide by Selective Etching of $\mathrm{Al}_{3} \mathrm{C}_{3}$ from Nanolaminated $\mathrm{Zr}_{3} \mathrm{Al}_{3} \mathrm{C}_{5}$. Angew. Chemie Int. Ed. 55, 5008-5013 (2016).

35. Zhou, J. et al. Synthesis and Electrochemical Properties of Two-Dimensional Hafnium Carbide. ACS Nano 11, 3841-3850 (2017).

36. Nowotny, V. H. Strukturchemie einiger Verbindungen der Übergangsmetalle mit den elementen C, Si, Ge, Sn. Prog. Solid State Chem. 5, 27-70 (1971).

37. Nowotny, H., Rogl, P. \& Schuster, J. C. Structural chemistry of complex carbides and related compounds. J. Solid State Chem. 44, 126-133 (1982).

38. Naguib, M. et al. New Solid Solution MAX Phases: $\left(\mathrm{Ti}_{0.5}, \mathrm{~V}_{0.5}\right)_{3} \mathrm{AlC}_{2},\left(\mathrm{Nb}_{0.5}, \mathrm{~V}_{0.5}\right)_{2} \mathrm{AlC}$, $\left(\mathrm{Nb}_{0.5}, \mathrm{~V}_{0.5}\right)_{4} \mathrm{AlC}_{3}$ and $\left(\mathrm{Nb}_{0.8}, \mathrm{Zr}_{0.2}\right)_{2} \mathrm{AlC}$. Mater. Res. Lett. 2, 233-240 (2014).

39. Schuster, J. C., Nowotny, H. \& Vaccaro, C. The ternary systems: CrAlC, VAlC, and TiAlC and the behavior of H-phases ( $\left.\mathrm{M}_{2} \mathrm{AlC}\right)$. J. Solid State Chem. 32, 213-219 (1980).

40. Liu, Z. et al. $\left(\mathrm{Cr}_{2 / 3} \mathrm{Ti}_{1 / 3}\right)_{3} \mathrm{AlC}_{2}$ and $\left(\mathrm{Cr}_{5 / 8} \mathrm{Ti}_{3 / 8}\right)_{4} \mathrm{AlC}_{3}$ : New MAX-phase Compounds in TiCr-Al-C System. J. Am. Ceram. Soc. 97, 67-69 (2014).

41. Anasori, B. et al. $\mathrm{Mo}_{2} \mathrm{TiAlC}_{2}$ : A new ordered layered ternary carbide. Scr. Mater. 101, 5- 
7 (2015).

42. Anasori, B. et al. Two-Dimensional, Ordered, Double Transition Metals Carbides (MXenes). ACS Nano 9, 9507-9516 (2015).

43. Meshkian, R. et al. Theoretical stability and materials synthesis of a chemically ordered MAX phase, Mo2ScAlC2, and its two-dimensional derivate $\mathrm{Mo}_{2} \mathrm{ScC}_{2}$ MXene. Acta Mater. 125, 476-480 (2017).

44. Tao, Q. et al. Two-dimensional $\mathrm{Mo}_{1.33} \mathrm{C}$ MXene with divacancy ordering prepared from parent 3D laminate with in-plane chemical ordering. Nat. Commun. 8, 14949 (2017).

45. Dahlqvist, M. et al. Prediction and synthesis of a family of atomic laminate phases with Kagomé-like and in-plane chemical ordering. Sci. Adv. 3, e1700642 (2017).

46. Meshkian, R. et al. W-Based Atomic Laminates and Their 2D Derivative $\mathrm{W}_{1.33} \mathrm{C}$ MXene with Vacancy Ordering. Adv. Mater. 30, 1706409 (2018).

47. Tao, Q. et al. Atomically Layered and Ordered Rare-Earth i-MAX Phases: A New Class of Magnetic Quaternary Compounds. Press

48. Naguib, M. et al. New Two-Dimensional Niobium and Vanadium Carbides as Promising Materials for Li-Ion Batteries. J. Am. Chem. Soc. 135, 15966-15969 (2013).

49. Persson, I. et al. Tailoring Structure, Composition, and Energy Storage Properties of MXenes from Selective Etching of In-Plane, Chemically Ordered MAX Phases. Small 14, 1703676 (2018).

50. Naguib, M. MXenes: A New Family of Two-Dimensional Materials and its Application as Electrodes for Li-ion Batteries. (Drexel University, 2014).

51. Tran, M. H. et al. Adding a New Member to the MXene Family: Synthesis, Structure, and Electrocatalytic Activity for the Hydrogen Evolution Reaction of $\mathrm{V}_{4} \mathrm{C}_{3} \mathrm{~T}_{x}$. ACS Appl. Energy Mater. acsaem.8b00652 (2018). doi:10.1021/acsaem.8b00652

52. Ghidiu, M. et al. Synthesis and characterization of two-dimensional $\mathrm{Nb}_{4} \mathrm{C}_{3}$ (MXene). Chem. Commun. 50, 9517-9520 (2014).

53. Yang, J. et al. Two-Dimensional Nb-Based $\mathrm{M}_{4} \mathrm{C}_{3}$ Solid Solutions (MXenes). J. Am. 
Ceram. Soc. 99, 660-666 (2016).

54. Soundiraraju, B. \& George, B. K. Two-Dimensional Titanium Nitride $\left(\operatorname{Ti}_{2} \mathrm{~N}\right)$ MXene: Synthesis, Characterization, and Potential Application as Surface-Enhanced Raman Scattering Substrate. ACS Nano 11, 8892-8900 (2017).

55. Lakhe, P. et al. Process Safety Analysis for $\mathrm{Ti}_{3} \mathrm{C}_{2} \mathrm{~T}_{x}$ MXene Synthesis and Processing. Ind. Eng. Chem. Res. 58, 1570-1579 (2019).

56. Ghidiu, M., Lukatskaya, M. R., Zhao, M.-Q., Gogotsi, Y. \& Barsoum, M. W. Conductive two-dimensional titanium carbide 'clay' with high volumetric capacitance. Nature 516, 78 (2014).

57. Liu, F. et al. Preparation of $\mathrm{Ti}_{3} \mathrm{C}_{2}$ and $\mathrm{Ti}_{2} \mathrm{C}$ MXenes by fluoride salts etching and methane adsorptive properties. Appl. Surf. Sci. 416, 781-789 (2017).

58. Liu, F. et al. Preparation of High-Purity $\mathrm{V}_{2} \mathrm{C}$ MXene and Electrochemical Properties as Li-Ion Batteries. J. Electrochem. Soc. 164, A709-A713 (2017).

59. Alhabeb, M. et al. Guidelines for Synthesis and Processing of Two-Dimensional Titanium Carbide ( $\mathrm{Ti}_{3} \mathrm{C}_{2} \mathrm{~T}_{x}$ MXene). Chem. Mater. 29, 7633-7644 (2017).

60. Halim, J. et al. Transparent Conductive Two-Dimensional Titanium Carbide Epitaxial Thin Films. Chem. Mater. 26, 2374-2381 (2014).

61. Karlsson, L. H., Birch, J., Halim, J., Barsoum, M. W. \& Persson, P. O. Å. Atomically Resolved Structural and Chemical Investigation of Single MXene Sheets. Nano Lett. 15, 4955-4960 (2015).

62. Sun, W. et al. Electrochemical etching of $\mathrm{Ti}_{2} \mathrm{AlC}$ to $\mathrm{Ti}_{2} \mathrm{CT}_{\mathrm{x}}(\mathrm{MXene})$ in low-concentration hydrochloric acid solution. J. Mater. Chem. A 5, 21663-21668 (2017).

63. Yang, S. et al. Fluoride-Free Synthesis of Two-Dimensional Titanium Carbide (MXene) Using A Binary Aqueous System. Angew. Chemie Int. Ed. (2018).

64. Lu, J. et al. $\mathrm{Ti}_{\mathrm{n}+1} \mathrm{C}_{\mathrm{n}} \mathrm{MXene}$ with fully saturated and thermally stable $\mathrm{Cl}$ terminations. (2019).

65. Li, M. et al. An Element Replacement Approach by Reaction with Lewis acidic Molten 
Salts to Synthesize Nanolaminated MAX Phases and MXenes. (2019).

66. Urbankowski, P. et al. Synthesis of two-dimensional titanium nitride $\mathrm{Ti}_{4} \mathrm{~N}_{3}$ (MXene). Nanoscale 8, 11385-11391 (2016).

67. Urbankowski, P. et al. 2D molybdenum and vanadium nitrides synthesized by ammoniation of 2D transition metal carbides (MXenes). Nanoscale 9, 17722-17730 (2017).

68. Ghidiu, M. et al. Ion-Exchange and Cation Solvation Reactions in $\mathrm{Ti}_{3} \mathrm{C}_{2} \mathrm{MXene}$. Chem. Mater. 28, 3507-3514 (2016).

69. Ghidiu, M. et al. Alkylammonium Cation Intercalation into $\mathrm{Ti}_{3} \mathrm{C}_{2}$ (MXene): Effects on Properties and Ion-Exchange Capacity Estimation. Chem. Mater. 29, 1099-1106 (2017).

70. Mashtalir, O. et al. Intercalation and delamination of layered carbides and carbonitrides. Nat. Commun. 4, 1716 (2013).

71. Mashtalir, O., Lukatskaya, M. R., Zhao, M.-Q., Barsoum, M. W. \& Gogotsi, Y. AmineAssisted Delamination of $\mathrm{Nb}_{2} \mathrm{C}$ MXene for Li-Ion Energy Storage Devices. Adv. Mater. 27, 3501-3506 (2015).

72. Omomo, Y., Sasaki, T., Wang, L. \& Watanabe, M. Redoxable nanosheet crystallites of $\mathrm{MnO}_{2}$ derived via delamination of a layered manganese oxide. J. Am. Chem. Soc. 125, 3568-3575 (2003).

73. Naguib, M., Unocic, R. R., Armstrong, B. L. \& Nanda, J. Large-scale delamination of multi-layers transition metal carbides and carbonitrides "MXenes". Dalt. Trans. 44, 93539358 (2015).

74. Anasori, B. et al. Control of electronic properties of 2D carbides (MXenes) by manipulating their transition metal layers. Nanoscale Horizons 1, 227-234 (2016).

75. Lipatov, A. et al. Effect of Synthesis on Quality, Electronic Properties and Environmental Stability of Individual Monolayer $\mathrm{Ti}_{3} \mathrm{C}_{2}$ MXene Flakes. Adv. Electron. Mater. 2, 1600255 (2016).

76. Natu, V., Clites, M., Pomerantseva, E. \& Barsoum, M. W. Mesoporous MXene powders 
synthesized by acid induced crumpling and their use as Na-ion battery anodes. Mater. Res. Lett. 6, 230-235 (2018).

77. Zhao, D. et al. Alkali-induced crumpling of $\mathrm{Ti}_{3} \mathrm{C}_{2} \mathrm{~T}_{\mathrm{x}}$ (MXene) to form $3 \mathrm{D}$ porous networks for sodium ion storage. Chem. Commun. 54, 4533-4536 (2018).

78. Maleski, K., Mochalin, V. N. \& Gogotsi, Y. Dispersions of Two-Dimensional Titanium Carbide MXene in Organic Solvents. Chem. Mater. 29, 1632-1640 (2017).

79. Hantanasirisakul, K. et al. Fabrication of $\mathrm{Ti}_{3} \mathrm{C}_{2} \mathrm{~T}_{x}$ MXene Transparent Thin Films with Tunable Optoelectronic Properties. Adv. Electron. Mater. 2, 1600050 (2016).

80. Dillon, A. D. et al. Highly Conductive Optical Quality Solution-Processed Films of 2D Titanium Carbide. Adv. Funct. Mater. 26, 4162-4168 (2016).

81. Ying, G., Dillon, A. D., Fafarman, A. T. \& Barsoum, M. W. Transparent, conductive solution processed spincast 2D $\mathrm{Ti}_{2} \mathrm{CT}_{x}$ (MXene) films. Mater. Res. Lett. 5, 391-398 (2017).

82. Collini, P., Kota, S., Dillon, A. D., Barsoum, M. W. \& Fafarman, A. T. Electrophoretic Deposition of Two-Dimensional Titanium Carbide (MXene) Thick Films. J. Electrochem. Soc. 164, D573-D580 (2017).

83. Natu, V., Sokol, M., Verger, L. \& Barsoum, M. W. Effect of Edge Charges on Stability and Aggregation of $\mathrm{Ti}_{3} \mathrm{C}_{2} \mathrm{~T}_{\mathrm{z}} \mathrm{MXene}$ Colloidal Suspensions. J. Phys. Chem. C acs.jpcc.8b08860 (2018). doi:10.1021/acs.jpcc.8b08860

84. Halim, J. et al. Synthesis of Two-Dimensional $\mathrm{Nb}_{1.33} \mathrm{C}$ (MXene) with Randomly Distributed Vacancies by Etching of the Quaternary Solid Solution $\left(\mathrm{Nb}_{2 / 3} \mathrm{Sc}_{1 / 3}\right)_{2} \mathrm{AlC} \mathrm{MAX}$ Phase. ACS Appl. Nano Mater. 1, 2455-2460 (2018).

85. Halim, J. et al. X-ray photoelectron spectroscopy of select multi-layered transition metal carbides (MXenes). Appl. Surf. Sci. 362, 406-417 (2016).

86. Dall'Agnese, Y. et al. High capacitance of surface-modified 2D titanium carbide in acidic electrolyte. Electrochem. commun. 48, 118-122 (2014).

87. Hope, M. A. et al. NMR reveals the surface functionalisation of $\mathrm{Ti}_{3} \mathrm{C}_{2} \mathrm{MXene}$. Phys. 
Chem. Chem. Phys. 18, 5099-5102 (2016).

88. Kajiyama, S. et al. Enhanced Li-Ion Accessibility in MXene Titanium Carbide by Steric Chloride Termination. Adv. Energy Mater. 7, 1601873 (2017).

89. Voigt, C. A., Ghidiu, M., Natu, V. \& Barsoum, M. W. Anion Adsorption, $\mathrm{Ti}_{3} \mathrm{C}_{2} \mathrm{~T}_{\mathrm{z}}$ MXene Multilayers, and Their Effect on Claylike Swelling. J. Phys. Chem. C 122, 23172-23179 (2018).

90. Li, T. et al. Fluorine-Free Synthesis of High-Purity $\mathrm{Ti}_{3} \mathrm{C}_{2} \mathrm{~T}_{\mathrm{x}}(\mathrm{T}=\mathrm{OH}, \mathrm{O})$ via Alkali Treatment. Angew. Chemie Int. Ed. 57, 6115-6119 (2018).

91. Naguib, M., Unocic, R. R., Armstrong, B. L. \& Nanda, J. Large-scale delamination of multi-layers transition metal carbides and carbonitrides "MXenes". Dalt. Trans. 44, 9353 9358 (2015).

92. Persson, I. et al. On the organization and thermal behavior of functional groups on $\mathrm{Ti}_{3} \mathrm{C}_{2}$ MXene surfaces in vacuum. 2D Mater. 5, 015002 (2017).

93. Lai, S. et al. Surface group modification and carrier transport properties of layered transition metal carbides $\left(\mathrm{Ti}_{2} \mathrm{CT}_{\mathrm{x}}, \mathrm{T}\right.$ : $-\mathrm{OH},-\mathrm{F}$ and $\left.-\mathrm{O}\right)$. Nanoscale 7, 19390-19396 (2015).

94. Lian, P. et al. Alkalized $\mathrm{Ti}_{3} \mathrm{C}_{2}$ MXene nanoribbons with expanded interlayer spacing for high-capacity sodium and potassium ion batteries. Nano Energy 40, 1-8 (2017).

95. Sang, X. et al. Atomic Defects in Monolayer Titanium Carbide $\left(\mathrm{Ti}_{3} \mathrm{C}_{2} \mathrm{~T}_{x}\right)$ MXene. ACS Nano 10, 9193-9200 (2016).

96. Gogotsi, Y. Chemical vapour deposition: Transition metal carbides go 2D. Nat. Mater. 14, 1079-1080 (2015).

97. Geng, D. et al. Controlled growth of ultrathin $\mathrm{Mo}_{2} \mathrm{C}$ superconducting crystals on liquid $\mathrm{Cu}$ surface. 2D Mater. 4, (2017).

98. Wang, Z. et al. Metal Immiscibility Route to Synthesis of Ultrathin Carbides, Borides, and Nitrides. Adv. Mater. 29, (2017).

99. Qi, Y. et al. Unique Transformation from Graphene to Carbide on Re(0001) Induced by 
Strong Carbon-Metal Interaction. J. Am. Chem. Soc. 139, 17574-17581 (2017).

100. Geng, D. et al. Direct Synthesis of Large-Area 2D $\mathrm{Mo}_{2} \mathrm{C}$ on In Situ Grown Graphene. Adv. Mater. (2017). doi:10.1002/adma.201700072

101. Qiao, J. Bin et al. One-step synthesis of van der Waals heterostructures of graphene and two-dimensional superconducting $\alpha-\mathrm{M} \mathrm{o}_{2}$ C. Phys. Rev. B 95, (2017).

102. Xu, C. et al. Strongly Coupled High-Quality Graphene/2D Superconducting $\mathrm{Mo}_{2} \mathrm{C}$ Vertical Heterostructures with Aligned Orientation. ACS Nano 11, 5906-5914 (2017).

103. Zeng, M. et al. 2D WC single crystal embedded in graphene for enhancing hydrogen evolution reaction. Nano Energy 33, 356-362 (2017).

104. Chaitoglou, S. et al. Insight and control of the chemical vapor deposition growth parameters and morphological characteristics of graphene/ $\mathrm{Mo}_{2} \mathrm{C}$ heterostructures over liquid catalyst. J. Cryst. Growth 495, 46-53 (2018).

105. Qiao, J.-B. et al. Two-dimensional spinodal interface in one-step grown graphenemolybdenum carbide heterostructures. Phys. Rev. Mater. 2, 054002 (2018).

106. Zhao, H. et al. Synthesis of molybdenum carbide superconducting compounds by microwave-plasma chemical vapor deposition. J. Appl. Phys. 123, (2018).

107. Deng, R. et al. Graphene/ $\mathrm{Mo}_{2} \mathrm{C}$ heterostructure directly grown by chemical vapor deposition. Chinese Phys. B 26, (2017).

108. Xiao, X. et al. Salt-Templated Synthesis of 2D Metallic MoN and Other Nitrides. ACS Nano 11, 2180-2186 (2017).

109. Joshi, S., Wang, Q., Puntambekar, A. \& Chakrapani, V. Facile Synthesis of Large Area Two-Dimensional Layers of Transition-Metal Nitride and Their Use as Insertion Electrodes. ACS Energy Lett. 2, 1257-1262 (2017).

110. Jia, J. et al. Ultrathin N-Doped $\mathrm{Mo}_{2} \mathrm{C}$ Nanosheets with Exposed Active Sites as Efficient Electrocatalyst for Hydrogen Evolution Reactions. ACS Nano 11, 12509-12518 (2017).

111. Zhang, F. et al. Plasma-enhanced pulsed-laser deposition of single-crystalline $\mathrm{Mo}_{2} \mathrm{C}$ ultrathin superconducting films. Phys. Rev. Mater. 1, 034002 (2017). 
112. Zhang, Z. et al. Substrate orientation-induced epitaxial growth of face centered cubic $\mathrm{Mo}_{2} \mathrm{C}$ superconductive thin film. J. Mater. Chem. C 5, 10822-10827 (2017).

113. Xu, C., Chen, L., Liu, Z., Cheng, H. M. \& Ren, W. Bottom-up synthesis of 2D transition metal carbides and nitrides. in Metal Carbides and Nitrides (MXenes): Structure, Properties, and Applications (eds. Gogotsi, Y. \& Anasori, B.) (Springer Nature, 2019).

114. Wang, L. et al. Magnetotransport Properties in High-Quality Ultrathin Two-Dimensional Superconducting $\mathrm{Mo}_{2} \mathrm{C}$ Crystals. ACS Nano 10, 4504-4510 (2016).

115. Song, S. et al. Magnetotransport in Ultrathin 2-D Superconducting $\mathrm{Mo}_{2} \mathrm{C}$ Crystals. IEEE Trans. Magn. 53, (2017).

116. Liu, Z. et al. Unique Domain Structure of Two-Dimensional $\alpha-\mathrm{Mo}_{2} \mathrm{C}$ Superconducting Crystals. Nano Lett. 16, 4243-4250 (2016).

117. Liu, Z. et al. Phase transition and in situ construction of lateral heterostructure of 2D superconducting $\alpha / \beta \mathrm{Mo}_{2} \mathrm{C}$ with sharp interface by electron beam irradiation. Nanoscale $\mathbf{9}$, 7501-7507 (2017). 